\title{
COVID-19: A review on molecular basis, pathogenic mechanisms, therapeutic aspects and future projections
}

\author{
*Muneeb A. Faiq $q^{1,2}$, Ashutosh Kumar ${ }^{1,3}$, Himanshu N. Singh ${ }^{1,4}$, Vikas Pareek ${ }^{1,5}$, Rizwana Qadri ${ }^{1,6}$, Khursheed Raza $^{1,7}$, \\ Chiman Kumari ${ }^{1,8}$, Ravi K. Narayan ${ }^{1,9}$, Pavan Kumar ${ }^{1,10}$ Maheswari Kulandhasamy ${ }^{1,11}$, Sada N. Pandey ${ }^{1,12}$ \\ 1- Etiologically Elusive Disorders Research Network, New Delhi, India \\ 2- New York University (NYU) Langone Health Center, NYU Robert I Grossman School of Medicine, New York, New York, \\ USA \\ 3- Department of Anatomy, All India Institute of Medical Sciences, Patna, India \\ 4- $\quad$ TAGC-INSERM, U1090, Aix Marseille University, Marseille, France \\ 5- $\quad$ National Brain Research Center, Manesar, Haryana, India \\ 6- $\quad$ Neuro-oncology Laboratory, Rockefeller University, New York, New York, USA \\ 7- $\quad$ Department of Anatomy, All India Institute of Medical Sciences, Deoghar, India. \\ 8- Department of Anatomy, Postgraduate Institute of Medical Education and Research (PGIMER), Chandigarh, India \\ 9- Department of Anatomy, All India Institute of Medical Sciences, Patna, India \\ 10- Department of Pediatrics, Medical University of South Carolina, Charleston, USA \\ 11- Department of Biochemistry, Maulana Azad Medical College (MAMC), New Delhi, India \\ 12- Department of Zoology, Banaras Hindu University (BHU), Varanasi, India
}

Keywords: Coronavirus, Pneumonia, COVID-19, Virus, Flu, Vaccine

The SARS-CoV-2 is a recently identified positive sense single stranded RNA virus and member of the coronavirus family of
viruses. It is thought to be the etiological factor for the ongoing COVID-19 pandemic. This virus is thought to have originated from
bats and acquired ability of human-to-human transmission. While SARS-CoV-2 is relatively benign, it has infected more than half
a million people (as of March $29^{\text {th }} 2020$ ) worldwide and the number of infected people continues to rise. More than 170 countries
have reported COVID-19 positive cases. With a mortality rate of less than both the previous coronavirus outbreaks, COVID-19 has
(conversely) caused the death of over 33,980 (as of $29^{\text {th }}$ March, 2020 at 22.00 hours EDT) people worldwide and the number is
increasing. Given the enormous impact of this virus on human health and wellbeing and consequent devastating impacts on world
trade, economics and quality of life, it is important to understand this virus better and get insight into its pathogenic mechanisms
which will aid in devising effective measure to curb its spread and predict future pattern of its interaction with humans. Though
very little is known about this SARS-CoV-2 but its mechanisms and patterns of spread can be speculated (with caution,
nevertheless) from what we know about its closest relatives SARS-CoV-1 (responsible for SARS-2002 epidemic) and MERS-CoV
(responsible for MERS-2012 epidemic). In the present review, we aim at bringing together the coherent and peer reviewed literature about the SARS-CoV-2 and its close relatives and try to understand its infection patterns and reconstruct its pathogenic mechanisms with anecdotes on diagnosis and future directions. We hope that this paper will serve the purpose of being a reliable source of information to scientists, clinicians and general public.

\section{Introduction}

In the last two months of 2019, some healthcare facilities in Wuhan province of China witnessed the inflow of patients with a collection of symptoms that resembled pneumonia (Chen et al., 2020; Wu et al., 2020; Chand et al., 2020, Huang et al., 2020). Their clinical presentation was similar to the that of severe acute respiratory syndrome coronavirus (SARS-CoV) that affected around 8,000 cases worldwide back in 2002-2004 (Wilder-Smith et al., 2020; Meo et al.,

*Correspondence: Muneeb A. Faiq
2020). A novel strain of coronavirus 2 (SARS-CoV-2) was subsequently isolated on January $7^{\text {th }}, 2020$ and its spread as a respiratory illness was reported (Huang et al., 2020; Zhu et al, 2020; Li et al., 2020). The disease was referred to as coronavirus disease-2019 (COVID-19) (WHO Report 11 Feb). Some evidence suggests that the virus originated from the wholesale seafood market (Phelan et al., 2020) named Huanan which was subsequently closed on January $1^{\text {st }}$, 2020. It was later reported that individual greater than 60 years of age and those with other comorbid conditions are susceptible to severe disease and may even die (Cascella et al., 2020). The emergence of 
coronavirus (SARS-CoV-2) outbreak in December 2019 which causes the disease known as the COVID-19 (CO-VI-D-2019 or CoronavirusDisease-2019) initially turned out to be an epidemic and was later declared a pandemic by the World Health Organization (WHO) on $11^{\text {th }}$ March, 2020 (Cascella et al., 2020; Cucinotta et al., 2020). It is believed that this outbreak originated from Wuhan, the capital of Hubei province in China (Phelan et al., 2020) with a population of around 11 million people. Wuhan has been a manufacturing hub owing to which it was designated as a creative city by UNESCO in the field of design in 2017 and has, therefore, been witnessing a substantial international visitorship. Being an active exporter city with a massive footfall might have been one of the reasons for the metamorphosis of COVID-19 epidemic into a pandemic. However, most of what we know about this virus is highly speculative so the claims about the origin of SARSCoV-2 are not confirmed (yet there is some reasonable evidence to support this premise). Since COVID-19 has now inflicted more than half a million people worldwide with more than 37,000 deaths (as of $30^{\text {th }}$ March, 2020) and negative impact on world economy, it has also led to panic and misinformation only to exacerbated fear and mismanagement (Mia \& Khan, 2020). The overall status quo of various aspects of COVID-19 is given in Figure 1. It is pertinent to mention that our group reported the mechanism of action of one of the positive sense RNA viruses (Zika virus) during the 2016 epidemic and implicated retinoic acid response elements in the etiopathogenesis of microcephaly (Faiq et al., 2016; Kumar et al., 2016). Hence, it appears that an all-inclusive review is needed that serves scientists and clinicians relatively coherent information on various aspects of COVID-19. This paper will also serve as an educational tool for general public who are perplexed by the contrasting reports that are coming from information sources that are not peer reviewed. SARSCoV-2 being similar to SARS-2002 virus (Wilder-Smith et al., 2020; Meo et al., 2020), we will aim at reconstructing the pathogenic mechanisms, symptomatology, clinical features, possible treatment regimens, measures of prevention, diagnostics and prognostic aspects in this write up. We will also try to provide relevant inputs from our research findings wherever possible. As a result, this manuscript will serve as an educational manual (not clinical advice) for healthcare workers and a reliable source of information for researchers and as well as general public.

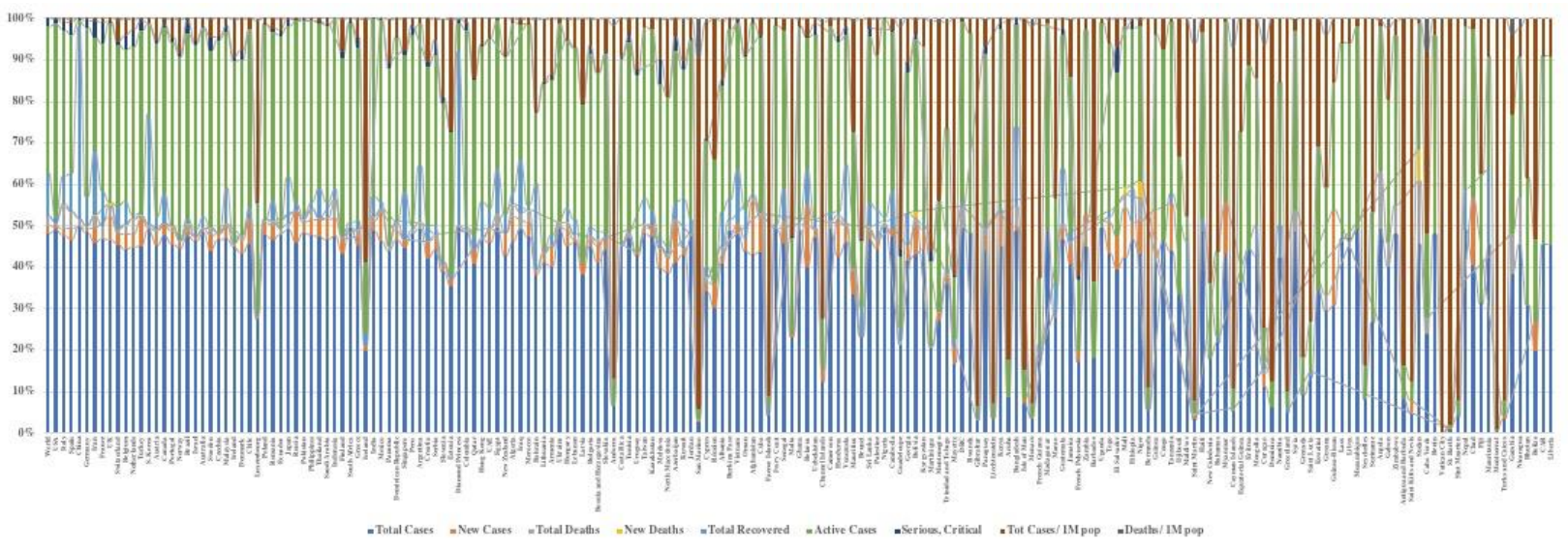

Figure 1: This figure displays the graphical representation of the status of reported, dead and treated cases worldwide. It shows country wise trend in comparison to the scenario worldwide. This graph represents total number of positive cases, new cases as on $30^{\text {th }}$ March, 2020, total number of deaths, total number of deaths reported within previous 24 hours, the number of cases recovered in each country, total number of active cases, and death normalized to each country's population. Each country represents its own percentile which can be compared to any other country around the world. Data source (https://www.worldometers.info/coronavirus/ and https://coronavirus.jhu.edu/). It must be understood that as new information comes in, data is subject to change.

\section{Epidemiology and Demographics}

The SARS-CoV-2 (novel Coronavirus-2019) described as the causative pathogen for the pandemic COVID-19 is thought to have originated in China (Chen et al., 2020; Wu et al., 2020) and new information is perpetually coming up to complete the mosaic of the picture of its various aspects. Multiple peer reviewed reports are rapidly being published, it turns out to be imperative to practice caution as the information about SARS-CoV-2 and COVID-19 is being updated fast (Mia \& Khan, 2020). Since SARS-CoV-2 is a recently identified virus and much is still not known about it, we felt that there is an ardent need of a comprehensive and all-inclusive overview that is scientifically accurate and relatively lucid. In addition to providing upto-date correct information and putting the subject into context (in terms of latest clinical research), such an endeavor would also help in addressing misinformation that is currently being circulated. This misinformation has been the source of panic and has presumably misled general public causing unnecessary stress and, in many cases, led to insensitivity towards the potential dangers posed by this virus 
(Mia \& Khan 2020; Geldsetzer, 2020). We assert what we know about this virus could change rapidly and, hence, it is important to look into the latest literature before making an opinion or suggesting any recommendations. However, given our understanding of virology and SARS-2002 and MERS-2012 epidemics we can make reasonable conclusions/hypotheses that would help us to contain this virus and bring down its fatality (Barry et al., 2002; Wilder-Smith et al., 2020; Peeri et al., 2020). It is important to be mindful of the misinformation and myths that have been spreading (as is always the case with epidemics and pandemics) and the need to educate not only patients, but caregivers, those in quarantine as well as the general public. In addition, clinicians are at high risk of catching SARS-CoV-2 infection as they are in regular contact of patients a vast majority of whom may be infected. This is particularly true with ophthalmologists ( $\mathrm{Li}$ et al., 2020; Wan et al., 2020) and otorhinolaryngologists.

\section{COVID-19 vis-à-vis other Coronavirus Outbreaks}

We know that the SARS-CoV-2 has significant similarities with the SARS-CoV-1 virus in many respects (Barry et al., 2002; Wilder-Smith et al., 2020; Peeri et al., 2020). The SARS-CoV-1 coronavirus was etiological basis of the outbreaks that led to SARS-2002 (de Wit et al., 2016). This outbreak generally identified as 2002-2004 SARS outbreak was an epidemic that originated from Foshan area in China and was characterized by severe acute respiratory syndrome (SARS) and led to the death of approximately 800 people worldwide. It is believed that 2002 coronavirus had bat as the original reservoir (probably a primary host) from where it is believed to have acquired the ability (most likely through mutations in its genome) to infect the intermediate host- Civet (a nocturnal mammal which was sold for meat in the markets of Yunnan province in China) where from the virus acquired the ability (most likely due to mutations in its genome) to be able to infect humans (Li et al., 2020; van Staden, 2020; Zhang et al., 2020).

At the outset, it is important to mention that coronaviruses are relatively benign, but they do show some significant respiratory effects (like viral rhinitis etc.) in humans (due to certain anatomical and physiological reasons explained later in this paper) and in certain cases they cause severe acute respiratory syndrome (SARS) (Chan et al., 2020; Huang et al., 2020). SARS is name given to a collection of conditions (usually caused by SARS-CoV) accompanied with severe systemic symptoms including muscle pain, headache, and fever, followed by the onset of respiratory symptoms (within 2 to 14 days), including cough, dyspnea and pneumonia with decreased number of lymphocytes in blood (Cleri et al., 2010; Darnell et al., 2004; Vijayanand et al., 2004). So, it appears that the virus often mutates (Denison et al., 2011; Holmes et al., 2004; Parvin et al., 1986) in certain imperative ways (owing to its highly dynamic RNA based genome and relatively low fidelity of the RNA-dependent-RNA polymerase (Elena et al., 2005; Venkataraman et al., 2018; Cameron et al., 2016) which is the enzyme it utilizes to replicate its genome) so as to be able to infect another host (an animal which serves as an intermediate host) other than its primary host. In case of SARS 2002 there was some evidence to show that the intermediate host was Civet (Hu et al., 2015; Chan \& Chan, 2013; Bolles et al., 2011; Wang et al., 2006; Tu et al., 2004; Xu et al., 2004). Why was Civet an intermediate host is not known but there seems to be a peculiar pattern that SARS-CoV-1 (SARS 2002) as well as SARS-CoV-2 (causative for COVID-19) both have nocturnal mammals (though this is based on speculations) an intermediate hosts indicating that humans might have to practice caution in future about the trade and use of nocturnal mammals, which in all possibility may be reservoirs of potentially dangerous viral pathogens (Shi \& Hu 2008) and in some cases may turn out to be fatal in the long run. There is every chance that we may be seeing epidemics and pandemics more frequently in the near future where more fatal pandemics might come from these intermediate nocturnal mammalian hosts. Is coronavirus a regular pathogen in nocturnal mammals is a question that needs to be pursued rigorously and might also hold answer to questions about the previous epidemics (SARS-2002, MERS-2012), the present one as well as those that are awaiting us in the future. From Civet (an intermediate host for SARS-2002), SARS-CoV-1 mutated enough to be able to infect humans (Li et al., 2020; van Staden, 2020; Zhang et al., 2020). This is not an isolated case in the history of human-virus interaction but has happened multiple times (through a process called zoonosis) (Weber \& Rutala, 1999; Salata et al., 2019; RodriguezMorales et al., 2020; Li \& Du, 2019; Chan et al., 2015; Huynh et al., 2012; Vijgen et al., 2005) and it did happen afterwards and is probably going to be a regular pattern in future (unless we develop necessary measures to curb the spread).

Almost a decade after the 2002 coronavirus SARS outbreak; in 2012 another similar eruption took place; the so-called Middle-Eastern Respiratory Syndrome (MERS) (Fehr et al., 2017; Sharif-Yakan et al., 2014; Milne-Price et al., 2014). MERS is also called the camel flu because its intermediate host was camel (Dawson et al., 2019; Bhatia et al., 2016). It was an epidemic caused by MERS-coronavirus (MERS$\mathrm{CoV}$ ) and its symptoms (fever, cough, diarrhea, shortness of breath or increased work of breathing) were similar to SARS-2002 but the mortality was significantly higher in comparison to COVID-19 (Cascella et al., 2020). The mortality rate of MERS was around 35 percent which means one third of the infected individuals died. By comparison COVID-19 is relatively benign with a mortality rate of 1 to 3 percent (though this percentage is changing with time and might actually be lower than the cited value). In case of MERS-2012, the origin (the primary host or the primary animal reservoir) is thought to be bat (again a nocturnal mammal) from where the virus acquired the ability to infect camel (the intermediate host which is not typically nocturnal but given the environment it lives in, it is also active during 
the nighttime). From camel it then mutated enough to be able to infect humans (Banerjee et al., 2019; Lau et al., 2018).

\section{Hosts and Infection Patterns}

From the above mentioned two major outbreaks, we arrive at the December-2019 outbreak which is referred to as COVID-19. In this case also the general belief again is that the virus originated from bats (Guo et al., 2020; Singhal et al., 2020) (primary host reservoir) where from it acquired the ability to infect pangolins (a nocturnal mammal of the order Pholidota generally known as scaly ant eater) as the intermediate hosts (Zhang et al., 2020; Fisher et al., 2020; Prompetchara et al., 2020; Li et al., 2020). Investigators are not yet sure if the intermediate host is pangolin indeed but this possibility seems to be highly likely (Zhang et al., 2020; Fisher et al., 2020; Prompetchara et al., 2020; Li et al., 2020). Again, from pangolin, this virus is thought to have mutated to the extent so that it acquired the ability to infect humans (Yuen et al., 2020; Zhang et al., 2020; Murdoch et al., 2020). A relevant aspect here is that these viruses (in addition to acquiring the ability to infect humans from the intermediate hosts) also acquire the ability for human-to-human transmission (Guo et al., 2020, Lai et al., 2020; Velavan et al., 2020; Mandal et al., 2020; Riou \& Althaus, 2020; Kakimoto et al., 2020). That is where the reason of the infection turning into an epidemic/pandemic comes from (Mandal et al., 2020; Riou \& Althaus, 2020) and that is where the philosophy and recommendation for quarantine is justified (Lewnard \& Lo, 2020; Parmet \& Sinha, 2020; Tang et al, 2020; Anderson et al., 2020). This might be one of the important areas of research to explore whether zoonosis has a parallel effect of human-to-human transmission and how can that be tackled in terms of vaccine development and/or by other means. In addition to human-to-human transmission, one of the major reasons for COVID19 to transmogrify into a pandemic may be that pangolin (which is believed to be the intermediate host of the virus) is highly trafficked around the world for medicinal purposes as its scales are thought to possess some healing properties (Lam et al., 2020; Sun et al., 2020). But pangolin being the intermediate host of SARS-CoV-2 is not confirmed (though there is evidence). This frequent trafficking of the intermediate host complemented with frequent international air-travel in the modern world (Craig et al., 2020, Zhuang et al., 2020; Wells et al., 2020) multiplies the risk of turning an epidemic into a pandemic (particularly so when the propensity of human-to-human transmission is high). This indicates that particular attention towards the intermediate hosts (especially nocturnal mammals or nocturnally active mammals) is important to curb the spread of the disease. The WHO (or other appellate bodies) needs to develop guidelines for international trafficking of such animals or at least update their guidelines and recommendation to this effect. At the same time, it is critical to understand that it is not only the intermediate host that imbibes the entire onus of the disease/infection/pathogen spread but many other factors (including personal hygiene, social behavior, medication, vaccination, policy making, airline protocols, cargo algorithms, public education, preparedness to outbreaks, training of the medical and paramedical staff etc.) do play a significant role (Wang \& Wu, 2018; Ameli, 2015; Erdem \& Unal, 2015; Quinn \& Kumar, 2014; de Almedia 2013; Howard \& Fletcher, 2012; Goldenthal et al., 1996; Aitken \& Jeffries, 2001). It is not sufficient to understand only the zoonosis though zoonosis might provide important clues about the spread of the virus and might also aid in prediction, and therefore, development of protocols to prevent outbreak of infective diseases in the future.

\section{Infectivity, Mortality and Morbidity}

One of the appropriate ways to approximate the severity of viral disease is to look into the mortality/fatality rates (Onder et al., 2020; Kelly \& Cowling, 2013; Yoshikura, 2012; Dombrovskiy et al., 2005). Such an approach is crucial and pertinent as it may influence the intensity of government response at the policy level and public reaction (Lo et al., 2018; Pelat et al., 2014). This in turn determines the intensity and nature of necessary steps to taken by all the institutions that have a stake in the outcome. Misinformation about this aspect may be one of the major reasons for panic potentially doing more harm than anticipated. Case fatality rate (CFR) or case fatality ratio is an important gauge as it allows us to make proper estimates (and hence neither over react nor under react in response to an epidemic) of the severity of the problem so that sufficient level of preparedness (for future) and response is initiated (Onder et al., 2020; Kelly \& Cowling, 2013; Yoshikura, 2012; Dombrovskiy et al., 2005; Lo et al., 2018; Pelat et al., 2014). By definition, CFR is an estimate of the percentage of deaths from a disease compared to the total number of people diagnosed positive for the disease during a particular time period. It is essential to present a caveat here that CFR can only be considered final when all the cases have been resolved (either died or recovered with no active cases being reported) (Atkins et al., 2015; Reich et al., 2012; Hop et al., 1997). By that definition, the CFR we are talking about COVID-19 in this paper is the preliminary CFR which may substantially change as the situations evolves. In the light of this, COVID-19 appears to pose some concerns with regards to the consensus on actual figures that are being reported by different research groups. The CFR can be estimated by the following equation:

$$
\mathrm{CFR}=\frac{\text { Total number of deaths }}{\text { Total number of positive cases }} \times 100
$$

For the SARS-2002, the CFR was estimated to be approximately 11 percent (Xu et al., 2004; Chan-Yeung \& Xu, 2003). The MERS-2012 had a much higher CFR of around 35 percent with a range from 25 to 43 percent (Al Awaidy \& Khamis, 2019; Alsolamy \& Arabi, 2015; Majumdar et al., 2014Hajjar et al., 2013). Now coming to the case 
fatality rate of COVID-19 (which is evolving every single day in the light of the highly dynamic nature of the latest figures) some reliable websites like the Worldometer (https://www.worldometers.info/coronavirus/) and the Johns Hopkins Coronavirus Resource Center (https://coronavirus.jhu.edu/) can be used to estimate the CFR in addition to a multitude of other parameters. WHO also release a situation report (https://www.who.int/emergencies/diseases/novel-coronavirus2019/situation-reports) every single day which is a reliable updated document with comprehensive useful information for general public and epidemiologists. The Johns Hopkins Coronavirus Resource Center, however, seems to be updated more frequently and it uses multiple sources for cross validation of the data. Hence that have robust protocols to update and analyze the data that are coming every single hour. As of now, CFR for COVID-19 comes out to be around 1 to 4.2 percent (Shim et al., 2020; Yang et al., 2020; Wilson et al., 2020; Dong et al., 2020; Li et al., 2020; Porcheddu et al., 2020). This is much lower than the CFR of the previous coronavirus outbreaks and hence should be mentioned whenever a comparison of COVID-19 is made with previous coronavirus outbreaks. Nevertheless, it is vital to point out that the estimate of 4.2 CFR for COVID-19 may actually be significantly lower than what it appears at the outset. This is because we don't, as of now, have any reliable estimates of the total number of people infections by this virus. This is due the fact that many SARS$\mathrm{CoV}-2$ infected individuals are asymptomatic and never get tested (Zhang et al., 2020; Lu et al., 2020; Mizumoto et al., 2020; Lin et al., 2020). The number of people who are infected with SARS-CoV-2 may be notably higher than the actual confirmed cases indicating that the CFR of COVID-19 may be notably less than the estimated rate. A critical dimension to note here is that most of the SARS-CoV-2 infections either present with mild symptoms or generate no symptoms at all meaning many individuals might have the infection which spontaneously gets healed without even the person having realized it (Zhang et al., 2020; Lu et al., 2020; Mizumoto et al., 2020; Lin et al., 2020). This phenomenon has both positive as well as negative effects. The positive aspect is that the virus is benign and, in many cases, does not require any intervention and/or hospitalization. This is in addition to having lower than estimated CFR. The negative aspect, conversely, is that an infected asymptomatic person can co-infected (unknowingly) many people who may develop symptoms and might require clinical attention. In this case we miss the opportunity to quarantine the asymptomatic carrier. Furthermore, many flu-like symptoms appear to be similar to COVID-19 (Cascella et al., 2020, Fisher et al., 2020; Guo et al., 2020; Bordi et al., 2020) which is an additional reason for general public to be apprehensive and a technical challenge for clinician to rule out parallel illness (for differential diagnosis) (Bordi et al., 2020). It remains the prerogative of the clinician to decide whether a particular set of symptoms in a patient presenting in the clinic looks like a COVID-19 case. If there are more cases with the same number of reported deaths in the population then the CFR might actually be lower than the estimated 1 to 4 .

One more critical marker that has imperative role to play in understanding the spread of the virus is the reproductive ratio or reproductive number. It is denoted by $\mathrm{R}_{O}$ and is different from reproductive rate. $R_{O}$ is the expected number of infections directly generated by a single positive case in a population (given all the individuals of the population are susceptible to the infection as no individual is vaccinated against the pathogen). $R_{O}$ is indispensable in understanding the severity of an emerging epidemic and may aid in certain useful predictions. In vernacular terms $\mathrm{R}_{\mathrm{O}}$ may be a direct measure of spreading ability (if we may use the term). This can be understood in terms of how many people can one infected person infect in turn. Though this number can vary vastly but, on an average, (or certain averaging measure) it is the probability estimate as to how many persons does one infected person infect (Delamater et al., 2019; van den Driessche, 2017; Ridenhour et al., 2014; Hefferman et al., 2005; Dietz, 1993). The $\mathrm{R}_{\mathrm{O}}$ of SARS-CoV-2 ranges from 2 to 3.5 (again this number is based on some initial reports when the actual number might change with time as new reports and epidemiological data become available) (Wang et al., 2020; Zhang et al., 2020, Liu et al., 2020). This indicates that if an infected person comes in contact with many people in a gathering (room, hall, office, public transport etc.) where the distance with other people is less than two meters, and if the person happens to sneeze or cough (thereby release respiratory droplets which contain the virus), there is a possibility that an average of approximately three persons will acquire the infection (though the actual number may vary vastly). It is to be borne in mind that this is a probabilistic case and the actual infectivity and the number of secondary infections may vary from situation-to-situation, society-tosociety, population-to-population, and age group-to-age group. If the people around are immunocompromised, then the infectivity and hence $\mathrm{R}_{\mathrm{O}}$ may be higher. If the environment (like the temperature, aircurrents, and humidity) is conducive for the virus to remain viable for long time and longer distance, this number can be higher. But at the outset it can be safely said that the $\mathrm{R}_{O}$ of SARS-CoV-2 (as far as the present estimates are concerned) is approximately 3 . This indicates that each infected person can infect three more people (during the course of his/her infection) who in turn can infect 3 persons each and so on. This initiates a self-replicating/amplifying chain (a chain progression with an amplification ratio of 3 ) which can be understood from Figure 2. It must be borne in mind that the $\mathrm{R}_{\mathrm{O}}$ of SARS-CoV-2 is estimated to be a range rather than a precise number as different sources have different data 


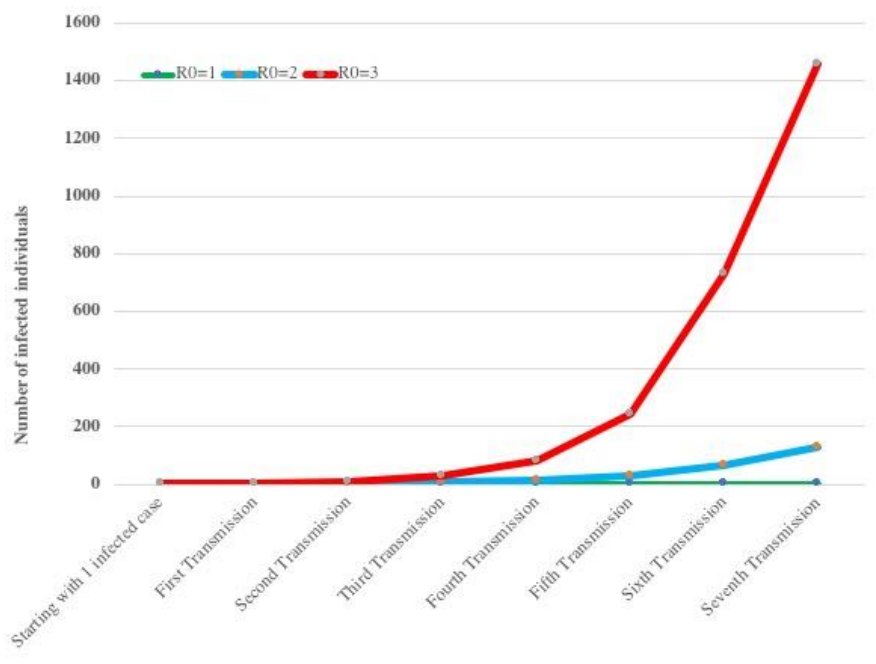

Different cycles of transmission starting with 1 infected individual

Figure 2: This graph is a schematic representation of the dynamics of infection spread in a population with different $\mathrm{R}_{0}$. This is a schematic representation and may have confounders which have not been considered for simplicity.

and hence different estimates. If we compare this number with influenza, the $\mathrm{R}_{O}$ of influenza virus is around 1.3 (meaning that one infected person generally infects slightly more than one person in turn) (Biggerstaff et al., 2014). This gives rise to a dynamic picture of COVID-19 with an exponential rise as shown by Figure 2. One of the major strategies to control the epidemic (now declared a pandemic by WHO) is to target the $\mathrm{R}_{\mathrm{O}}$ and thereby bring down the spreading ability. It appears that epidemiologists and clinical microbiologists have to pay attention to the strategies that affect $\mathrm{R}_{\mathrm{O}}$. Given the three major stages of the infection viz. exposure, latent infection and isolation after diagnosis, a mathematical model can also be applied to know how to

\begin{tabular}{|c|c|c|}
\hline S. No & Point of Contact & Consideration (Cai, 2020, Young, 2020, Zou, 2020, Ong, 2020) \\
\hline 1 & $\begin{array}{l}\text { Morning milk bags/milk crates/milk bottles (and } \\
\text { other groceries) }\end{array}$ & $\begin{array}{l}\text { There are no reports suggesting transmission. May contain droplets } \\
\text { released from the infected handlers. Wash with soap/sanitize the cover } \\
\text { of the pack and/or wash your hands for the assurance. }\end{array}$ \\
\hline 2 & Morning newspaper & $\begin{array}{l}\text { There are no reports suggesting spread of infection from newspapers. } \\
\text { You may avoid interpersonal sharing of it. }\end{array}$ \\
\hline 3 & Elevator buttons & $\begin{array}{l}\text { May contain virus. Avoid touching or sanitize your hands following } \\
\text { that. }\end{array}$ \\
\hline 4 & Handles of public transport & $\begin{array}{l}\text { May contain virus. Avoid touching or sanitize your hands following } \\
\text { that. }\end{array}$ \\
\hline 5 & Handles of apartment buildings & $\begin{array}{l}\text { May contain virus. Avoid touching or sanitize your hands following } \\
\text { that. }\end{array}$ \\
\hline 6 & Doorbells & $\begin{array}{l}\text { May contain virus. Avoid touching or sanitize your hands following } \\
\text { that. }\end{array}$ \\
\hline 7 & Car-door handles & $\begin{array}{l}\text { May contain virus. Avoid touching or sanitize your hands following } \\
\text { that. }\end{array}$ \\
\hline 8 & Door handles of buildings/gates & $\begin{array}{l}\text { May contain virus. Avoid touching or sanitize your hands following } \\
\text { that. }\end{array}$ \\
\hline 9 & Fruits/vegetables/market purchases & $\begin{array}{l}\text { There are no reports of transmission from any food products. Prefer } \\
\text { washing before use. }\end{array}$ \\
\hline
\end{tabular}

curb the spread (Mandal et al., 2020; Kucharski et al., 2020; Choi et al, 2020; Hellewell et al., 2020). Also, if we have a list of factors that affect (increase or decrease) the $\mathrm{R}_{O}$ then we may be able to bring down the number of cases and halt the spread of the virus by curbing the factors that increase $R_{O}$ while enhancing those that decrease $R_{O}$ washing hands regularly, by social distancing, staying away from crowds, sneezing in a proper way, coughing in a proper way (there are many instruction manuals available and many YouTube videos also). A list of such the factors that may potentially help in reducing the frequency of new infections and is given in Table 1 . This list is in no way exhaustive. 


\begin{tabular}{|c|c|c|}
\hline 10 & Counters at shops/offices etc. & $\begin{array}{l}\text { May contain virus. Avoid touching or sanitize your hands following } \\
\text { that. }\end{array}$ \\
\hline 11 & Bus/subway/train seats and handles & $\begin{array}{l}\text { May contain virus. Avoid touching or sanitize your hands following } \\
\text { that. }\end{array}$ \\
\hline 12 & Office pantry & $\begin{array}{l}\text { May contain virus. Avoid touching or sanitize your hands following } \\
\text { that. }\end{array}$ \\
\hline 13 & Office shared machines and equipment & $\begin{array}{l}\text { May contain virus. Avoid touching or sanitize your hands following } \\
\text { that. }\end{array}$ \\
\hline 14 & Public washrooms/toilets & $\begin{array}{l}\text { May be contaminated with virus. Avoid public washrooms/toilets or } \\
\text { ensure proper self-sanitization after use. }\end{array}$ \\
\hline 15 & Seats and benches in parks/gardens & $\begin{array}{l}\text { May contain droplets released from the infected visitors. Taking } \\
\text { precaution is advised. }\end{array}$ \\
\hline 16 & Playgrounds and the articles thereof & $\begin{array}{l}\text { May contain droplets released from the infected visitors. Avoid } \\
\text { touching or sanitize your hands following that. }\end{array}$ \\
\hline 17 & Housekeeping touching different surfaces & $\begin{array}{l}\text { May contain virus. Avoid touching or sanitize your hands following } \\
\text { that. }\end{array}$ \\
\hline 18 & Home delivery items & $\begin{array}{l}\text { There are no reports suggesting transmission. May contain virus. } \\
\text { Sanitize the cover of the pack and wash your hands for the assurance. }\end{array}$ \\
\hline 19 & Shopping bags & $\begin{array}{l}\text { May contain virus. Avoid touching or sanitize your hands following } \\
\text { that. }\end{array}$ \\
\hline 20 & Currency notes & $\begin{array}{l}\text { There are no such reports that virus spreads through currency notes. But } \\
\text { receiving or giving it someone Avoid touching or sanitize your hands } \\
\text { following that. }\end{array}$ \\
\hline 21 & All forms of public transport & $\begin{array}{l}\text { Avoid using public transports if possible, or use proper gears, as masks } \\
\text { and gloves, for protection. Sanitize yourself following that. }\end{array}$ \\
\hline 22 & Air around the infected person & $\begin{array}{l}\text { Virus is not known to pass in air but infected droplets can transmit it. } \\
\text { Keep a safe distance (about } 6 \text { feet). }\end{array}$ \\
\hline 23 & Clothes of the infected person & $\begin{array}{l}\text { May contain virus. Avoid touching or sharing, or sanitize your hands } \\
\text { following that. }\end{array}$ \\
\hline
\end{tabular}

Table 1: This table enumerates a comprehensive list of contacts that may potentially harbor the virus (SARS-CoV-2) for COVID-19 if these surfaces have come in contact with an infected person in the past 24 to 48 hours. It must be understood that such surfaces do not normally contain the virus. These points of contact harbor the virus only and only if they have come in contact with an infected person. If that is the case, then it might be expedient to avoid coming in contact with these surfaces. It might also be a good idea to try to disinfect these surfaces (wherever feasible) and also was your hands with soap immediately in case the individual comes in contact with infected surfaces. *There are many online resources that show how hands should be washed in order to effectively neutralize a pathogen. Few important reliable sources are the Johns Hopkins video (https://www.youtube.com/watch?v=IisgnbMfKvI) and WHO tutorial (https://www.youtube.com/watch?v=3PmVJQUCm4E).

One of the major ways to target $\mathrm{R}_{\mathrm{O}}$ is to quarantine the infected and suspected cases (Lauer et al., 2019; Lewnard \& Lo, 2020; Parmet \& Sinha, 2020; Tang et al, 2020; Anderson et al., 2020). Elemental to mention that it might be expedient for quarantine centers to preferably be separate building for positive and suspected cases as many negative cases (individuals who have not contracted the infection but are under the suspicion) might unnecessarily catch infection if quarantined with confirmed positive cases. Additionally, it has become evident to keep the quarantine centers well equipped with many facilities including food, bedding and recreation. Without these facilities there is every chance that the patient might develop severe distress symptoms potentially leading to psychological disorders (Parmet \& Sinha, 2020; Park \& Park, 2020) and future onset of post traumatic disorders. The quarantined individuals might also be apprehensive about their families and they need to assured about the wellbeing of their families. If the quarantine centers don't pay heed to these apparently unimportant (yet critical) issues, then some inmates might escape the quarantine and may be a potential threat to healthy population. Such cases have emerged from many places across the world and in certain circumstances became major reasons for the infection spread (though peer reviewed literature is yet lacking on this facet). 
Another critical aspect that warrants our attention is the Serial Interval (SI). SI may be defined as the time between successive cases (usually number of days) in a chain of infection transmission (Huber et al., 2016; Vink et al., 2914; Leevy et al., 2013; Donelly et al., 2011; Cowling et al., 2009; Vynnycky \& Fine, 2000; ten Asbroek et al., 1999). It is vital to analyze $R_{O}$ in relation to SI because SI also has a major role to play in infection spread and also in certain important aspects of the natural history of the infection. At time $\mathrm{T} 0$ a person gets infected but does not develop symptoms. Then on a certain day (we designate as D0) the patient starts to have symptoms. Let us suppose that the symptoms stop on Day 14 (D14). Now somewhere during this period of being inoculated by the virus, the patient starts spreading the infection to other people. Let us call the initially infected person P1 and the next infected person P2. Now if P2 gets infected somewhere between D0 to D14 (let us call it Dx). Dx of P1 is the T0 of the patient $\mathrm{P} 2$. Now the time between the symptom of onset of patient P1 and the symptoms of onset of P2 is what can be referred to as SI. How is SI relevant and why is it important? This is because the length of SI is inversely proportion to the morbidity (or danger index so to speak) of the virus. SI has an inverse relationship with the pace at which the infection becomes an epidemic (and spreads in a population) and subsequently a pandemic (given its transmission internationally which is now an ardent possibility in light of the frequency of air travel that has increased in the past two decades). The SI for COVID-19 has been estimated to be different in different studies but as a general statement it is around 5 to 7.5 days. Different studies have reported different estimates (Wilder-Smith et al., 2020; Du et al., 2020; Nishiura et al., 2020). As a measure of comparison SI for influenza is approximately
2.5 (Vink et al., 2014; Levy et al., 2013; Cowling et al., 2009). This indicates that the time interval from onset of symptom in P1 and the time of onset of symptom in P2 is 7.5 days (as against 2.5 days for influenza). A comparison of the SI of various viruses is given in Table 2.

It can now be concluded that high $\mathrm{R}_{\mathrm{O}}$ and low $\mathrm{SI}$ is indicative of high pace of a viral infection turning into an epidemic (or pandemic). In case of COVID-19 it can be roughly estimated that the infection from one person infecting other person takes around 7.5 days so on and so forth. By almost 22 days this single person become the source of 27 infections and the pattern follows an exponential curve as shown in Figure 2. It looks like that the SI of COVID-19 is significantly larger than influenza which may be one of the reasons that it took a considerably longer time for people and authorities around the world to realize how severe the threat is. At the same time, this must be borne in mind that owing to this significantly longer SI, the disease may peak months after the expected peak time which, in turn, indicates that we have to be cautious of any silent, asymptomatic infections apart from the relapse cases (Chen et al., 2020; Zhou et al., 2020; Sun et al., 2020). In many populations around the world this infection has been able to transform itself into an epidemic because it gave the public and medical practitioners impression that the infection is not spreading quickly and hence there is not much to worry. Had there been an SI of 2.5, there would have been a rapid upsurge of cases and that would have led to chaos. On the other hand, it would have prompted authorities and people around to world to take quick measures and not to neglect the potential danger of the spread of this virus.

\begin{tabular}{|c|c|c|c|c|c|c|c|c|c|c|}
\hline Outbreak & $\begin{array}{l}\text { Place of } \\
\text { origin }\end{array}$ & $\begin{array}{l}\text { Causative } \\
\text { agent }\end{array}$ & $\begin{array}{l}\text { Type of } \\
\text { causative } \\
\text { agent }\end{array}$ & $\begin{array}{l}\text { Primary } \\
\text { Host }\end{array}$ & $\begin{array}{l}\text { Intermedia } \\
\text { te Host }\end{array}$ & $\begin{array}{l}\text { Total } \\
\text { number of } \\
\text { cases } \\
\text { reported } \\
\text { worldwide }\end{array}$ & $\begin{array}{l}\text { *Total } \\
\text { number of } \\
\text { deaths } \\
\text { worldwide }\end{array}$ & $\begin{array}{l}\text { Case } \\
\text { Fatality } \\
\text { Rate }\end{array}$ & $\begin{array}{l}\# R_{0} \\
\text { Value }\end{array}$ & $\begin{array}{l}\text { Series } \\
\text { Interval } \\
\text { (Days) }\end{array}$ \\
\hline $\begin{array}{l}\text { SARS- } \\
2002\end{array}$ & $\begin{array}{l}\text { Believed } \\
\text { to be } \\
\text { China }\end{array}$ & Coronavirus & $\begin{array}{l}\text { Positive } \\
\text { strand RNA } \\
\text { Virus }\end{array}$ & Bat & $\begin{array}{l}\text { Believed to } \\
\text { be civet }\end{array}$ & 8000 & 800 & $11 \%$ & $\begin{array}{l}0.19- \\
1.08\end{array}$ & 7 \\
\hline $\begin{array}{l}\text { COVID- } \\
2019\end{array}$ & $\begin{array}{l}\text { Believed } \\
\text { to be } \\
\text { China }\end{array}$ & Coronavirus & $\begin{array}{l}\text { Positive } \\
\text { strand RNA } \\
\text { Virus }\end{array}$ & $\begin{array}{l}\text { Assumed } \\
\text { to be Bat }\end{array}$ & $\begin{array}{l}\text { Assumed to } \\
\text { be pangolin }\end{array}$ & $\begin{array}{l}* 770,293 \\
\text { (as on } \\
\text { March } 30^{\text {th }} \text {, } \\
2020 \text { ) }\end{array}$ & 18,906 & $4.4 \%$ & $2-3.5$ & 7.5 \\
\hline
\end{tabular}

Table 2: This table displays the characteristics of COVID-19 pandemic in comparison to other coronavirus outbreaks. Though there are many similarities yet there are important differences also. There is also a wide variation in mortality rate (CFR). It appears that all these related outbreaks have the pathogen originated from bat and there seems to be a correlation with nocturnal mammals in terms of the primary reservoir host as well as the intermediate host. The $\mathrm{R}_{0}$ value and the SI mentioned here is arbitrary as it is supposed to change as COVID-19 situation evolves. *Different sources have given different figures about the number of cases and the number of deaths. Additionally, this number of cases and death is changing very rapidly and hence the values of case fatality rate as well as $\mathrm{R}_{0}$. $\# \mathrm{R}_{0}$ is varied for different populations and the absolute $\mathrm{R}_{0}$ can only be calculated when no active case is reported. The $\mathrm{R}_{0}$ reported here is a preliminary value which may change. 


\section{Modes of Transmission}

Coming to the modes of transmission, it must be understood that we don't know much about the routes through which this virus gets transmitted but extrapolating from SARS-2002 experience fecal-oral (Wu et al., 2020; Gu et al., 2020; Han et al., 2020; Yeo et al., 2020) and respiratory routes (Yang and Wang, 2020; Qu et al., 2020; Pend et al., 2020; Lai et al., 2020) can be hypothesized. An infected person touching surfaces without proper precautions and then another person coming in contact with such surfaces is one of the major routes of transmission (Guo et al., 2020, Frieden \& Lee, 2020). The use of public bathrooms, for this reason, should be restricted/avoided and the cleaning personnel should be disinfecting the bathroom surfaces frequently. Also, there should be a notice of instructions outside (on the door) as well as inside (on the mirrors) of the bathrooms (a pictorial instruction poster may even be better) that would help to bring down the spread of the infection. Poorly sanitized buildings with problems in the plumbing system may also be responsible for the infection transmission though sufficient evidence in support of this notion is not available.

The robustly indicated mode of transmission is the respiratory route (which includes, but is not limited to coughing and sneezing). This mode of infection also called airborne infection enables the virus (via droplets, aerosol etc.) to spread from one individual to another. Though there are important differences between droplet infection and aerosol mediated as the size, half-life and distance to which they remain viable but it can be speculated that maintaining physical distance from an infected/suspected person is warranted. When the infection remains asymptomatic for a considerable number of cases, it becomes evident why everyone should maintain distance from each other. That is the basis of social distancing. A retrospective approach to understand this mechanism has been very helpful in the past and is likely to be helpful in containing the present and future airborne disease outbreaks. Though this mode of inter-human disease transmission is often indicated (yet inconclusive in many studies) but it aids in developing strategies to curb the spread of viruses that spread through aerosols and droplets. Such studies also help in devising isolation guidelines. The Center for Disease Control and Prevention has detailed out the measure that can help in preventing the transmission of this infection (https://www.cdc.gov/coronavirus/2019-ncov/index.html). It must be understood that certain facts about the respiratory droplets (the droplets which are produced when a person coughs and/or sneezes) and their life-cycle (or half-life so to speak) and spread have indispensable bearing on the design of isolation protocols, quarantine recommendations, personal protection equipment design (and robustness), treatment plans and preventive measures. Respiratory droplets (droplets $>5 \mu \mathrm{m}$ in diameter which tend to fall to the ground under the effect of gravity, and therefore be a vehicle for infection transmission over short distances of approximate distance of $\leq 2 \mathrm{~m}$ ) have the potential to travel in air some distances without settling down (Liu et al., 2017; Stikianakis \& Drossinos, 2010; Xie et al., 2009; Li et al., 2009; Xie et al., 2007; Hogg \& Hustan, 2006; Duguid, 1946). In most of the cases the distance these respiratory droplets are able to move without settling are 3 to 6 feet (1 to 2 meters) (Duguid, 1946; Stikianakis \& Drossinos, 2010). This distance immediately sets the optimum length for social distancing. It is to be understood that the distance is not everything. These respiratory droplets can settle on surfaces where they can survive for 24 hours or more (Marr et al., 2019; Warnes et al., 2015; Nikitin et al., 2014; Fernstrom et al., 2013; Greatorex \& Goldbatt, 2011; Rapport 1991; van Doremalen et al., 2020; Roosa et al., 2020; Duan et al., 2003). If these surfaces come in contact with a healthy person, in that case the person may get infected. Again, it is worth mentioning that such a possibility is not absolutely inevitable but is highly probable. Such surfaces include tables, computer keyboards, chairs, handles, clothes, etc. This list can be enormous and hence a clinician needs to make a comprehensive list of these potential surfaces and have it circulated (or at least displayed in the clinics). We have made a list of the possible points of contact for coronavirus (SARS-CoV-2) with the hope that this might serve some purpose to clinicians and the relevant healthcare workers. It will also be useful for the general public. Table 1 depicts the same. However, a caveat is necessary here that we have tried to make a comprehensive list and the mere mention of any article/surface in the table does not necessarily indicate that the surface is contaminated with SARS-CoV2. But if the surface has come in contact with an infected person within the previous, there is high probability that the surface might be contaminated and hence caution should be observed. The time these droplets stay in the air before they settle down is approximately three hours (van Doremalen et al., 2020) indicating that the volume around the infected person who releases droplets (after coughing and/or sneezing) in the air is potentially infective within two meters radius for about three hours. If this principle is understood, a majority of the problem is likely tackled. It is important to mention here that asymptomatic person infected with SARS-CoV-2 is also capable of producing these cough droplets containing the virus and also has the same ability to infect other people as that of the infected person with symptoms of the disease.

\section{Pathogenic mechanisms}

Once the virus makes its way to the respiratory tract, it reaches the alveoli where its primary target are the type II pneumocytes (Cascella et al., 2020; Tian et al., 2020; Gralinski \& Baric, 2015; Qian et al., 2013; Zhang et al., 2020; Mossel et al., 2008). Type I pneumocytes play role in gas-exchange (Ward et al., 1984) while as the type II pneumocytes produce an important substance called surfactant (a substance that reduces the surface tension within the alveoli and hence contributes to the elastic properties of the lungs thereby making breathing relatively easy and effortless) (Sugahara, 1994; Helewski \& 
Konecki, 1989). Type II pneumocytes are the primary targets of the virus which infects the cells and initiates its multiplication inside the body. The S-spike of the virus binds with the angiotensin converting enzyme 2 (ACE-2) on the surface of the pneumocytes type 2 (Ortega et al., 2020). ACE-2 is a member of the ACE family and a type I transmembrane metallocarboxypeptidase and a regulator of the ReninAngiotensin system and hence an important target for management of hypertension. It is distributed in many tissues in the body including lung, kidney, gastrointestinal (GI) tract, and cardiovascular system (Chen et al., 2020; Roca-Ho et al., 2017; Varagic et al., 2014; Tikellis \& Thomas, 2012; Ocaranza \& Jalil, 2012; Hamming et al., 2007). This might explain the systemic manifestations, renal compromise, GI dysregulation, cardiovascular dysfunction and multi-organ failure in certain SARS-CoV-2 cases. activated through the release of its RNA. Internalization of the virus through binding the ACE-2 receptor and taken up by the cells as a vacuole can be inhibited by using the drug chloroquine. Chloroquine and hydroxychloroquine are FDA-approved antimalarial drugs developed in 1934 and used during World War II. Being an antimicrobial in nature, many researchers are skeptic about its efficacy in COVID-19 yet some other scientists have expressed optimism. In addition to aiding in evoking immune response, chloroquine presumably alters the $\mathrm{pH}$ at the surface of the alveolar cells thereby inhibiting the binding of SARS-CoV-2 to ACE-2 and hence preventing the entry of the virus into the cells and consequently breaking the potential vicious trail of metabolic and pathological events that is to follow. In a study published a few days back, it was demonstrated that hydroxycholoroquine in combination with azithromycin (an

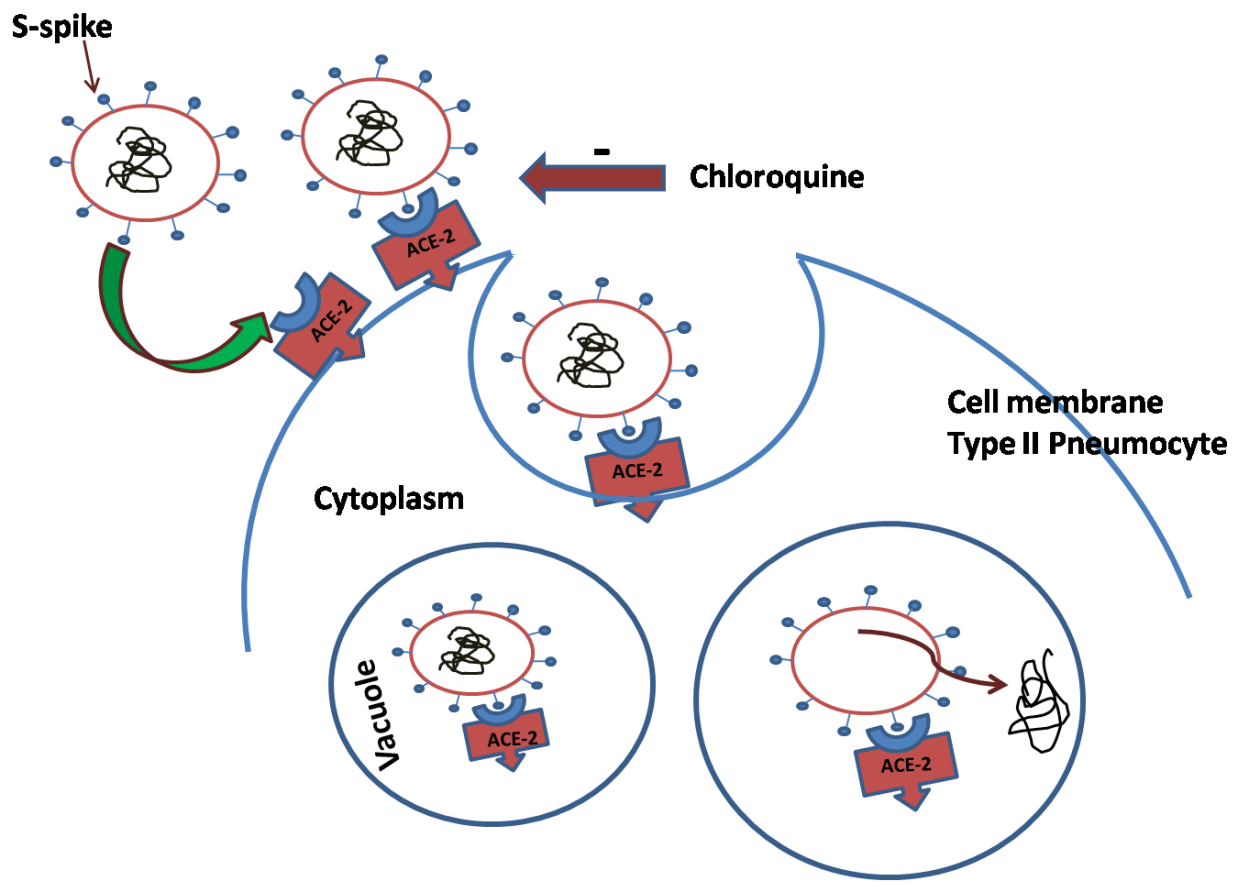

ACE-2 is the primary target for SARS-CoV-2 and the onset of various symptoms including the respiratory distress can be explained in terms of the virus targeting the ACE-2 receptors. Figure 3 shows a preliminary depiction of the mechanism. After the virus (S-spike) binds to ACE-2, the receptor-ligand complex is internalized. This way the virus finds its way to the cytoplasm of the pneumocyte where it gets antibacterial) had better efficacy than hydroxycholoroquine alone. These results are; however, preliminary and further evidence is required to draw any unambiguous conclusion. At the outset, it appears that antimalaria agents and their combinations with antibacterials may not show any encouraging effects with respect to treatment of COVID19 but carefully designed clinical trials might have better answer to this question. At this point, it ma

Figure 3: A depiction of the mechanisms of SARS-CoV-2 entry into the cells (in this case pneumocyte type II). The virus has many structures out of which the most important are the S-spike that binds with the ACE-2 receptor on the surface of the cells. After binding with the ACE-2 on the cell membrane, the virus is taken into the cell by endocytosis (invagination and formation of vacuole). Once the virus reached the cytoplasm, it releases its genetic material (RNA) which is then acts as a messenger RNA and protein translation starts by utilizing the host machinery. This way the virus enters pneumocyte type II and is then replicated to kill the cell and get released into the extracellular milieu. 
also be important to mention remdesivir as a potential therapeutic agent which has known antiviral activity. Again, carefully conducted clinical trials will provide better perspective and clear answers. Given the previous experience with SARS-2002 and MERS-2012, it appears that remdesivir holds some promise. With this premise, National Institute of Allergy and Infectious Disease, USA has initiated a clinical trial with remdesivir and there have been other clinical trials (two phase III clinical trials) started with this drug in Asia also. Results are awaited and hence it is too early to conclude anything. It must be borne in mind that self-medication with these potential drugs may prove to be harmful and these medications should be consumed only by the advice of the professionals who have the necessary training and license to prescribe these drugs. Chloroquine has many side effects (headache, anorexia, diarrhea, GI upset, skin irritation, hair loss, etc.). The side effects of remdesivir include nausea, vomiting and increase in liver enzymes which may or may not indicate hepatic damage but may interfere in tracing the prognosis. On a side note, many pharmacological agents have been found to be useful in modulation of ACE-2. Though it is not evident, but does provide some support to the notion that ACE modulators may hold some supportive promise in prophylaxis and treatment of viral diseases mediated through ACE-2 binding. As an example, activation of sympathetic nervous system happens in viral infections which leads to fever and other systemic changes. ACE-2 plays an important role in regulating cholinergic signaling and cardiovascular and sympathetic responses within the rostral ventrolateral medulla (Deng et al., 2019). With this outlook, a hypothesis about the possible use of citicoline as a supportive therapy can be argued. Though experimental evidence is lacking for this proposition.

Many of the COVID-19 cases present with extra-pulmonary symptoms. This is presumably because ACE-2 is expressed in many cell types in the body. ACE-2 mediated functions imbibe a wide array of physiological events that can serve as an integrative model to reconstruct the COVID pathology. Figure 4 shows the enrichment map of ACE-2 functions in human physiology providing an indication of the possible pathophysiological events that might occur during the course of SARS-CoV-2 infection. An overview of the most common symptoms associated with COVID-19 are depicted in Figure 5. In elderly individuals (those more than 60 years of age) and those with diabetes or coronary artery diseases, COVID-19 has been reported to lead to serious cardiac complications (like heart failure) in certain cases. Acute liver and kidney failures also have been reported to be in the gamut of complications in some (but not all) infected individuals. GI related symptoms (like diarrhea, nausea, and vomiting) are commonly present, and sometimes the only presenting features in some infected individuals. This is where ACE-2 mediated pathology of COVID-19 finds additional justification. The binding of SARS-CoV-2 to ACE-2 may potentially explain these extrapulmonary symptoms in COVID-19.

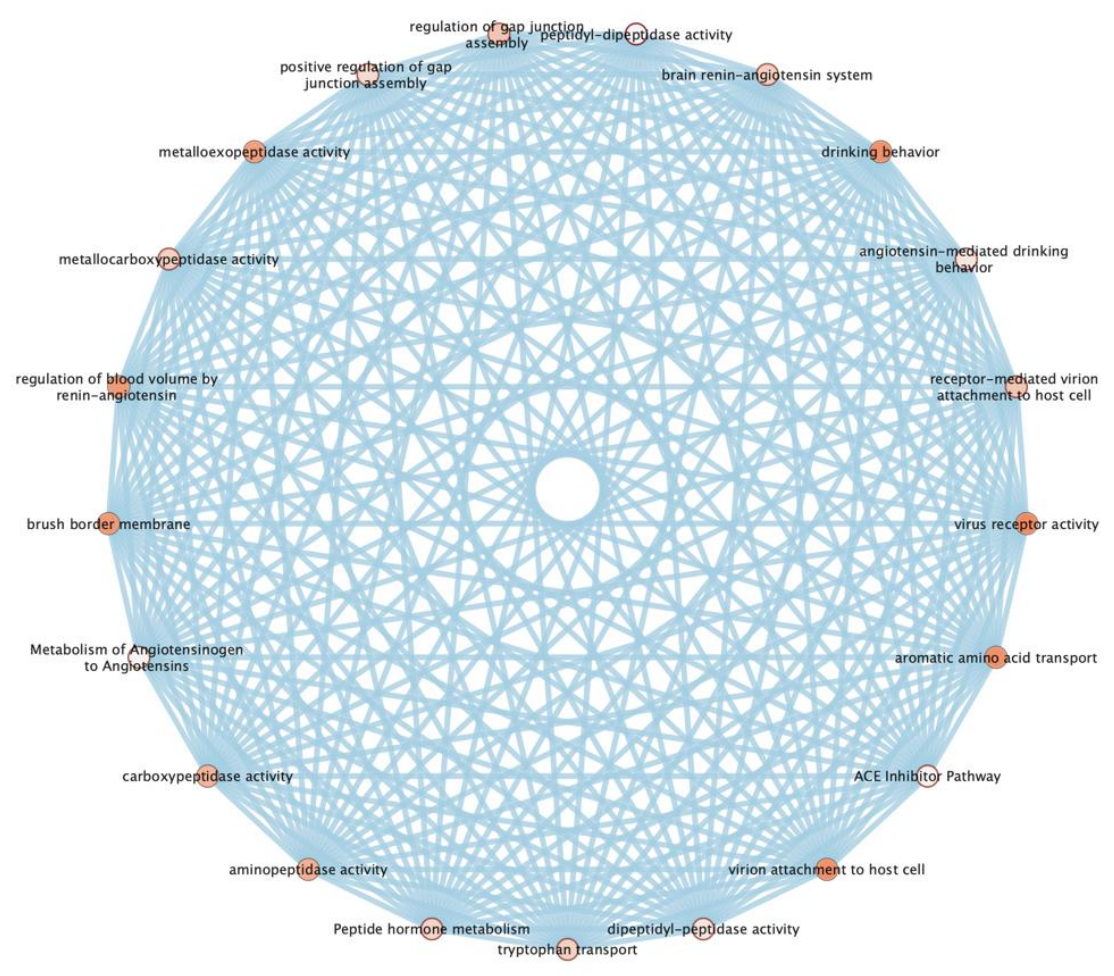


Figure 4: Enrichment map of ACE-2 functions in human physiology providing an indication of the possible pathophysiological events that might occur during the course of SARS-CoV-2 infection. It may also provide an idea about the various systems that need to be monitored during the course of COVID-19 in a patient.

ACE-2 catalyzes the cleavage of angiotensin I into angiotensin 1-9, and angiotensin II into the vasodilator angiotensin 1-7 which are the active components of the RAS. RAS pathway is the central homeostatic mechanism responsible for maintaining hemodynamic balance of the body and involves major organs like lungs, heart, liver, and kidneys (Tikellis \& Thomas, 2012). These are the organs where the RAS components are synthesized leading to the formation of relevant metabolites. Dysregulation of RAS is said to be implicated in pathogenesis of hypertension and in cardiac and renal failures, and diabetes mellitus (Tikellis \& Thomas, 2012). Literature suggests tissue specific enrichment of ACE-2 in all of these organs (Hamming et al.,
2004). It appears to be plausible that SARS-CoV-2 binding mediated dysfunction of ACE-2 and subsequent dysregulation of RAS may be the etiological and pathogenic basis for cardiovascular, renal, and hepatic symptoms appearing in COVID-19 patients (Tomlinson ET AL., 2020, Zheng, Zhang, Xie, 2020). Known physiological dysfunction of RAS with aging can explain why complications related to these organs are more prevalent in the aged populations (Tikellis \& Thomas, 2012) and why SARS-CoV-2 is relatively benign towards youngsters and kids. This is besides the fact that younger populations have lesser involvement of comorbid conditions in the pathology and consequent complications.

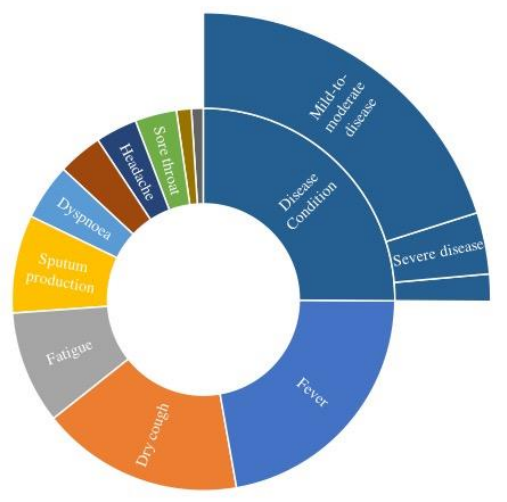

Figure 5: This figure shows the relative frequency of symptoms associated with coronavirus positive cases. However, symptoms may vary from population to population and may also be different in different geographic regions. This figure also demonstrated the number of cases that are mild those that are severe. This gives an idea that most of the COVID-19 positive cases have mild symptoms. Data source: WHO-China join commission report; Chen et al., 2020, Guan et al., 2020; Huang et al., 2020.

Similarly, ACE-2 tropism based mechanism of SARS-Cov-2 can be speculated to be involved in the pathogenesis of GI symptoms. The enterocytes in the lining epithelium and glandular cells in the GI tract show high intensity of ACE-2 expression (Hamming et al., 2004). Evidence in animal models suggests ACE-2 mediated regulation of aminoacid transporters known to regulate secretory and absorptive function in GI tract (Hashimoto et al., 2012). Also, the enrichment of ACE-2 expression in intestine tissue has been implicated in inflammatory bowel diseases (IBDs) (Khajah et al., 2016) which present with similar GI symptoms as in COVID-19 (Hashimoto et al., 2012). The virus mediated dysregulation of ACE-2 signaling, therefore, seems to have a strong bearing on the mechanism of the pathogenesis of GI symptoms in COVID-19 cases. GI symptoms were also reported in SARS-CoV-1 (Shi et al., 2005) (virus responsible for SARS epidemic of 2002) which binds at ACE-2 (Turner et al., 2004).

As already mentioned that SARS-CoV-2 is a positive sense single stranded RNA virus (Fehr \& Perlman, 2015; Yuen et al., 2020; Khan et al., 2020, Lai et al., 2020). It requires RNA-dependent-RNA polymerase to multiply its genetic material. This may provide rationale for the potential use of Remdesivir for treatment of COVID-19 and studies are, therefore, underway (Elfiky, 2020; Dong et al., 2020; AlTawfiq et al., 2020; Gordon et al., 2020). Ramdesivir was also used in the treatment of Ebola -virus infections (Mulangu et al., 2019; Tchesnokov et al., 2019). The multiplication of COVID-19 virus does not depend on a DNA phase and hence the DNA phase may not exist. Although we have produced some evidence that certain positive sense 
RNA viruses may act through activation of endogenous reverse transcriptase to archive their genome in the host genome in the form of DNA (Faiq et al., 2018; Kumar et al., 2016) but that does not seem to be the case with SARS-CoV-2. This is perhaps the reason that antiretroviral therapy may be thought of some potential to manage COVID-19.

Once the RNA is released into the cytoplasm of type 2 pneumocytes, it acts as a messenger RNA and utilizes the host cell ribosome machinery to translate the polyproteins which are cleaved by specific enzymes (proteases) into active protein particles including the S-spike (against which antibodies are being designed for therapeutic/vaccination purposes) (Ibrahim et al., 2020; Ahmed et al., 2020; Liu et aal., 2020; Tian et al., 2020), the capsid and various other protein moieties (Vankadari \& Wilce, 2020; Kim et al., 2020) requisite for the assemblage of the active and viable virus (Mclntyre et al., 2018; Poltronieri et al., 2015; Hyodo \& Okuna, 2016; Richards \& Jackson, 2013; Wang \& Li, 2013; Ahlquist et al., 2003). It appears that certain protease-inhibitors can have potential to inhibit this step and, therefore, may act as potential drugs for COVID-19 treatment (Martinez, 2020). Ritonavir, a potent protease inhibitor (which has been used to treat HIV infection) may serve as a potential candidate for such investigations (Cao et al., 2020; Yao et al., 2020; Lim et al., 2020). One of the translated proteins of SARS-CoV-2 is the RNA-dependent-RNA polymerase which leads to the synthesis of multiple RNA copies (which are the genome of the virus). Given the enough copies of the RNA being produced within the cytoplasm of the host cells (which in this case are pneumocytes), and the enough proteins important for the viral structures, these two moieties combine to give rise to hundreds and thousands of viral particles within the cell (Zinzula \& Tramontano, 2013). Once that occurs, the cell either activates its apoptotic mechanism or is being destroyed by the macrophages. This leads to the release of the multiple copies of the viable virus into the extracellular matrix and interstitial fluid where the new/amplified progeny of the virus has now the opportunity to infect other type 2 pneumocytes. Given the enough number of viruses being produced, they infect type 2 pneumocytes of other alveoli and also enter the blood circulation to invade other cell types (particularly those expressing ACE-2). Then the coronavirus mediated pathophysiology (Freeman, A. M., \& Leigh, 2020 ) potentially leading to pneumonia sets in.

Once the type 2 pneumocyte gets ruptured, it may (in all possibilities) attract macrophages through the production of inflammatory mediators. The so activated macrophages (Naeem et al., 2020; Herbert et al., 2010; Losa et al., 1999; Driscoll et al., 1995) could then secrete specific cytokines including interleukin 1 (IL1), interleukin 6 (IL6) and tumor necrosis factor alpha (TNF- $\alpha)$. These so released cytokines, mediate their effects through moving into the bloodstream and immediately causing the dilation of blood vessels by acting on endothelial cells of the microvasculature around the alveoli. The dilation of the smooth muscles of the alveolar microvasculature can then lead to increase in the permeability of the blood vessels around the alveoli. One of the parallel events in this is the endothelial cell contraction which leads to increase in the size of the pores in between the endothelial cells composing the microvasculature. The increased gap/pore size reflects in terms of the increased permeability.

If the vasodilation and increased capillary permeability is ensued then the leaking of plasma into the interstitial spaces and also into the alveoli becomes a robust possibility. As this fluid accumulates around the alveoli, it leads to a compressive pressure around the alveoli causing difficulties in their expansion during breathing and consequently respiratory distress. The centripetal pressure around the alveoli makes it difficult for the infected person to breathe normally. Some of the increased interstitial fluid (caused due to hyper permeability of the endothelial cells in the alveolar capillaries) seeps into the inside of the alveolar spaces which interferes with functioning of the surfactant. The production of surfactant is already diminished due to the infection and subsequent death of type 2 pneumocytes (which are primarily the surfactant producing cells). Increase of fluid accumulation could also lead to decrease in the surfactant concentration which may precipitate a surfactant deficiency subsequently causing distress in breathing (increased work of breathing). The accumulation of this fluid in the alveoli and consequent drop in the surfactant concentration within the alveolar spaces is called alveolar edema. Such a condition leads to increase in alveolar surface tension and hence respiratory distress and difficulty in breathing. Increase in surface tension leads to increase in collapse pressure (as per the Laplace's law $\mathrm{P}=2 \mathrm{~T} / \mathrm{R}$ where $\mathrm{P}$ is pressure, $\mathrm{T}$ is surface tension and $\mathrm{R}$ is the radius of the alveoli). This indicates that such a condition is a mathematical certainty for respiratory distress as a result of alveolar collapse. This combination of factors eventually leads to decrease in the primary function of the alveoli (the gasexchange) and consequent fall in the partial pressure of oxygen (hypoxemia; $\mathrm{pO}_{2}$ ). Thus, hypoxemia may present as one of the complications in the natural history of COVID-19.

Apart from macrophages, the inflammatory mediators released by the demise of type 2 pneumocyte tends to bring in neutrophils which cross the alveolar membrane and start concentrating within the alveolar sac to neutralize the viruses released into the alveolar space. One of the major mechanisms through which neutrophils act on viruses is to release reactive oxygen species (ROS) and proteases which in certain quantities neutralize the virus but in overwhelming proportions may lead to an excess ROS and proteases. Such a condition, not only neutralizes the viruses but also destroys the cells lining the alveoli (including both type 1 and type 2 pneumocytes). As a result, the structure and therefore the function of the alveoli is disturbed. Since type1 pneumocytes play important role in gas-exchange (Ward et al., 
1984; Powers \& Dhamon, 2020), there is a significant drop in gasexchange and hence it precipitates severe hypoxemia (and a consequent drop in the partial pressure of oxygen ensues). As the cells lining the alveoli get destroyed and as the infiltration of neutrophils and macrophages (as a result of inflammatory mediators released by the rupture of pneumocytes) leads to increase in the cell debris within the alveolar space; the alveoli, as a result, have accumulated cell debris, degraded protein, neutrophils, macrophages. This condition (referred to as consolidation) severely hampers gas-exchange at the level of the alveoli again leading to drop in partial pressure of oxygen and hypoxemia.

The release of immense quantities of IL1 and IL6 seep into the bloodstream. Since this release of TNF- $\alpha$, IL1 and IL6 comes from a vast number of alveoli within the lungs, it may lead to a significant increase of these compounds in the blood and hence travel to the central nervous system. The hypothalamus, in response to the increased concentration of these mediators responds by releases prostaglandins thereby resetting the body thermostat leading to increase in body temperature (fever; an important presenting symptom of COVID-19). That is how the two important features (respiratory distress and fever) may be generated in the SARS-CoV-2 infection (Cascella et al., 2020; Wan et al., 2020; He et al., 2020). The consolidation (of the cellular debris in the alveoli) needs to be moved out of the lungs and one of the mechanisms of throwing such debris out in humans is coughing. Hence, this debris may cause cough (initially dry cough but can be productive cough also) and the COVID-19 patients present with this as one of the symptoms. Hence another symptom in these patients (dry and subsequently productive cough). It is worth mentioning that though there are certain symptoms and clinical features that are frequently associated with COVID-19 but the actual symptoms/clinical features may vary and there are numerous permutations of symptoms and clinical features that a patient can present with. These symptoms range from asymptomatic to cough, sneezing, sore throat, fever, pneumonia (hence need for ventilator), lymphopenia, drop in $\mathrm{pO}_{2}$, hepatic dysfunction, $\mathrm{pH}$ dysregulation, renal compromise, cardiovascular manifestations (tachycardia), GI upset, inflammatory phenotype, etc (Cascella et al., 2020; Wan et al., 2020; He et al., 2020).

The low $\mathrm{pO}_{2}$ in the blood may trigger a peculiar chemo response or stimulation of chemoreceptors which, in turn, can initiate a reflux to stimulate the sympathetic nervous system (SNS) to increase the heart rate. This way the patient might also present with increase in pulse rate. The COVID-19 patient might also present with tachycardia. Drop in $\mathrm{pO}_{2}$ and subsequent SNS response precipitate an increase in respiratory rate which may also be one of the symptoms in the presenting patient.

Till now we were discussing the situation when the disease is still under control. Now let us see when all these issues enter into the severe category. As more and more alveoli get involved and increasing number of alveoli witness consolidation, most of the inflammatory markers (IL1, IL6 and TNF- $\alpha$ ) seep into the blood stream and there may be an upsurge of battery of inflammatory markers in the blood. As a result, the inflammation within the lungs (pulmonary inflammation) can now lead to systemic inflammatory response which is a potential for sceptic shock. A condition that started off with pneumonia may harbor the potential to culminate at the multiple system organ failure.

\section{Diagnostics}

In the light of the above given mechanism, it can be understood that a patient might present with fever, cough, shortness of breath and sometimes with upper respiratory tract infection symptoms (sore throat, headache etc.) and also with GI symptoms (nausea, vomiting, and diarrhea). According to our studies (our unpublished data), all these symptoms can be explained in terms of the ACE-2 mediated pathogenic mechanism of COVID-19. However, it must be understood that the primary symptoms are the triad of fever, cough and shortness of breath (Cascella et al., 2020; Wan et al., 2020; He et al., 2020). This is despite the fact that the patient may present with symptoms other than this trial. In that case, the clinician faces a strong diagnostic challenge with a high risk of misdiagnosis or delay in differential diagnosis. It may, therefore be advisable to order radiological examinations like chest X-ray and CT (Bai et al., 2020; Li et al., 2020; Yoon et al., 2020) and look for signs of consolidation (the so-called ground glass patter) while the other diagnostic test results are awaited. Sometimes the whole set of clinical features looks like a flu and in most of the cases it is a flu indeed. Asking a few questions to the patient might help the clinician navigate through the differential diagnosis. Some of the questions that need to be asked are:

1. Have you been in contact with any person who has been diagnosed positive for COVID-19?

2. Have you travelled recently?

3. Have you recently been to some country where there was an outbreak of coronavirus?

All these questions (and many others) are likely to aid the clinician to figure out the clinical history that might prove to be vital for establishing the diagnosis. After asking the questions, it appears to be coherent to run a flu test. The test for influenza is straightforward. Just taking a nasopharyngeal swab and testing for influenza $\mathrm{A}$ and influenza $\mathrm{B}$ (or as might be the WHO recommendation in different countries) is all that is needed to rule out influenza. So, one of the first steps in the differential diagnosis of COVID-19 arguably be ruling out influenza.

The realtime polymerase chain reaction (RT-PCR) is a sophisticated test which needs to be done by a highly competent person who is well trained and experienced to run the test otherwise there is always chance of having high number of false positive and/or false negative results. 
The RT-PCR based diagnostic methods have a varied sensitivity indicating that we can very well have false positive and false negative cases. But this test is still the gold standard for the diagnosis of COVID-19 (Li et al., 2020; Chan et al., 2020; Lan et al., 2020; Fang et al., 2020). Another issue with RT-PCR is that this test involves a number of steps and hence takes a lot of time (a few days in most of the cases). Since the results come after some time, the severity of the symptoms (in certain cases) might worsen in the interim. The selection of the sample to be harvested for RT-PCR is also a challenge. However, many kits come with detailed and precise instructions about the nature (nasopharyngeal swab, glossopharyngeal swab, aspirate, blood or sputum) and amount of sample to be taken. The instructions about the method of harvesting sample, is however, lacking in the manual of many of the available kits. Another related test that can be done which is relatively expensive is the Nucleus Acid Amplification Test (NAAT). The principle of this test is similar to RT-PCR but it gives results relatively earlier than RT-PCR.

It is important to know the patient status in terms of various aspects and hence would be critical to evaluate the markers that are associated with high mortality rate. Figure 6 depicts the conditions associated with high mortality rate based on the number (percentage) of death in confirmed positive cases. A complete blood count (CBC) is one of the first tests to run in this list. A peculiar finding that we may come across in this case is neutropenia. Though this seems to be unexpected as there should be neutrophilia in case of infections but here the story often runs counter to the general belief. Lymphopenia often adds support to suspicion for a viral etiology. A comprehensive metabolic panel (CMP) may also be ordered (which is actually a combination of basic metabolic panel and liver function tests). In severe cases the results often present with increase in Alanine aminotransferase (ALT; also called SGPT), aspartate aminotransferase (AST; also called SGOT) and bilirubin. BMP can provide information about the renal status in addition to glucose levels. Occasionally, due to neutropenia and other parallel conditions, patients suffering from acute viral infection may also contract a parallel bacterial infection due to pneumonia and that is perhaps the reason of increased efficacy of hydroxychloroquine when administered in combination with azithromycin (in such a treatment protocol, a comprehensive renal supported might be warranted). Such bacterial infections can be and should be tested by estimation of procalcitonin (a peptide precursor of the hormone calcitonin which is produced by many cells of the body in response to bacterial infections). It is important to remember that procalcitonin is almost exclusive to bacterial infections. In isolated COVID-19 infection the procalcitonin level is normal but if the infection is accompanied with a super infection of a bacterium then the procalcitonin levels might be elevated and hence an antibacterial regimen may be complemented with an antiviral treatment protocol.

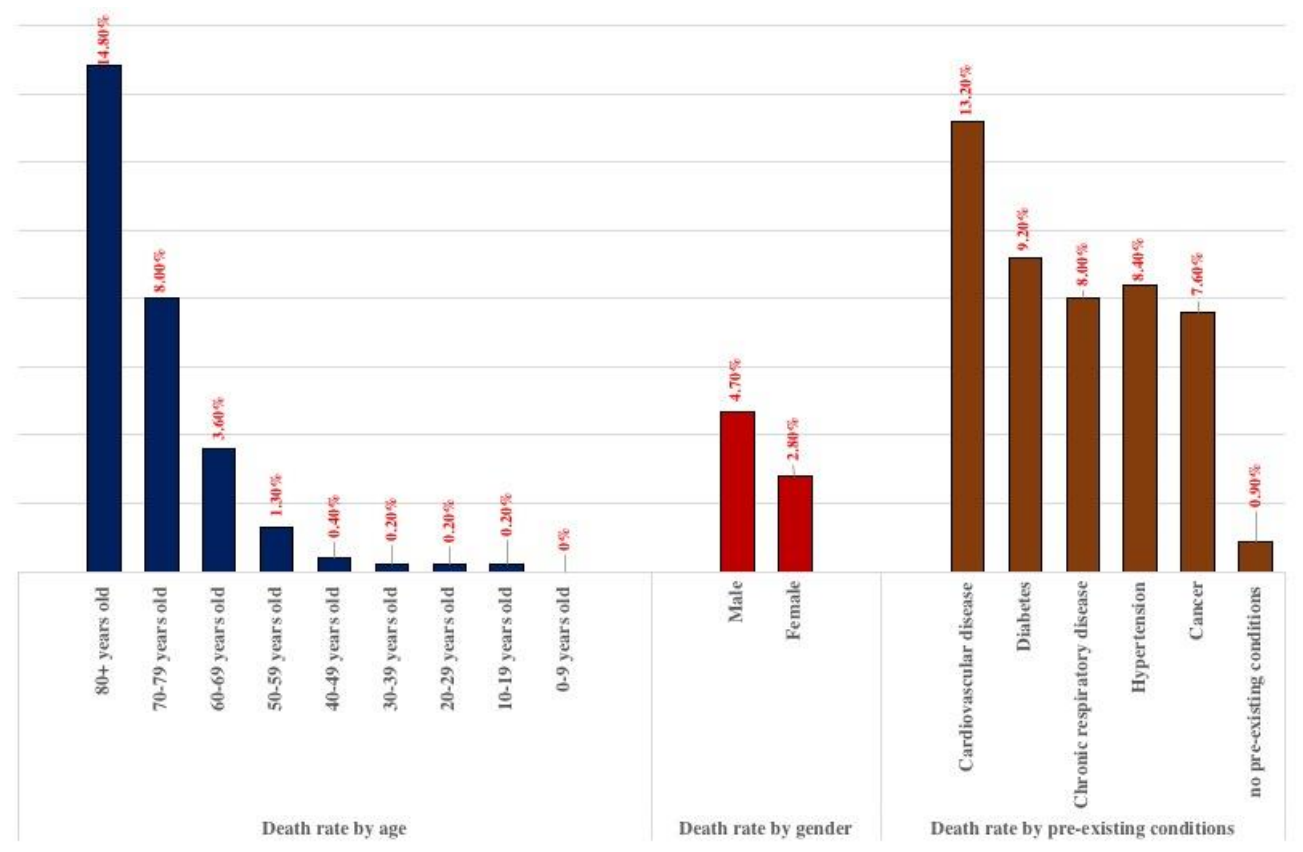

Figure 6: A depiction of the relative association of various parameters with the death rate in COVID-19 positive cases. The figure shows that though the mortality rate increases with age but younger individuals may also progress to intense disease severity and death. Masculine gender appears to have higher mortality rates than the feminine gender. Also, cardiovascular comorbidity has been found to be highly associated with high mortality (Data source: https://coronavirus.jhu.edu/data/mortality and https://www.worldometers.info/coronavirus/). 
It is also pertinent to evaluate the patient's general inflammatory markers. Though these markers may have limited role in diagnosis but they do have a significance in understanding the prognosis. These markers are c-reactive protein (CRP) and erythrocyte sedimentation rate (ESR). Both of these might be elevated. Levels of IL1, IL6, and TNF-alpha can also be evaluated to get an idea about the severity of the proinflammatory phenotype. Elevation in lactate dehydrogenase can also be an additional finding (this can be elevated in response to hypoxemia), so can be the elevation of D-dimer. There may even be an elevation in ferritin levels. All these markers may be elevated in COVID-19 patients and their elevation may be associated with relatively higher mortality rates. However, this is not always the case. Continued hypoperfusion to cardiac muscles due to drop in blood pressure (secondary to vasodilation and hyperpermeability of the endothelial cells) might also cause the elevation of troponin I, troponin $\mathrm{C}$ and $\mathrm{CK}-\mathrm{MB}$ in the blood. This also is an indicator of a relatively higher mortality rate. All these conditions are associated with hemodynamic instability.

There are some imaging tests that might also be helpful in understanding the patient's condition and consequently managing the disease better. These tests can be chest X-ray, CT scan (Bai et al., 2020; Li et al., 2020; Yoon et al., 2020; Cheng et al., 2020; Li et al., 2020; Dai et al., 2020) and USG (Moro et al., 2020; Buonsenso et al., 2020; Soldati et al., 2020; Buonsenso et al., 2020). To this effect, CT might be the most important and the most sensitive. Though $\mathrm{CT}$ is not specific to COVID-19 but it is highly sensitive (Yang et al., 2020; Ai et al., 2020). In a chest X-ray, a characteristic picture of a ground glass opacity might be visible. In a CT, the ground glass opacities are also visible in the peripheral lung fields but there are two additional features that can be picked up by CT. One of these features is the areas of alveolar consolidation indicating pneumonia. In addition to this the unique pattern called the 'crazy paving pattern' (associated with interstitial fluid accumulation, membrane thickening compounded with alveolar interstitial edema) can also be seen. In addition to these tests, point of care ultrasound can also be done where a pleural line thickening can be observed. In this case the ultrasound may also be associated with lines of pulmonary edema (also called the B lines). The consolidation with air bronchograms is also visible on the ultrasound. In this context radiological consultation might prove to be very helpful (Zhou et al., 2020; Wu et al., 2020; Yu et al., 2018; Gao et al., 2017; Kobayashi \& Mitsudomi, 2013)

\section{Future Directions}

In terms of the management, the first and foremost thing that should be done is to get proper education and clear doubts. To this effect Table 3 provides probable answers to certain frequently asked questions that might help in clearing doubts. Second is the recommendation for a person suspected of having COVID-19 (even if the results of the test are not yet confirmed) is to self-quarantine. It might be a good idea to give a phone call to the healthcare provider rather than personally visiting the clinic (Telemedicine services, 2020; Portnoy \& Elliot 2020; Smith et al., 2020; Hollander \& Carr, 2020). The clinician might then decide if the patient should arrive physically in the clinic. Also, the airline industry has to be prepared for future epidemics and they have to be mindful of their role in the transmission of critical and highly infective human pathogens (Wilf-Miron et al., 2003; Zhang et al., 2020; Craig et al., 2020). The personnel working with the aviation industry need to be especially trained to be able to curb any epidemic and keep it from spreading to international and global levels. The aviation authorities have to develop a course module/training mandatory for all the personnel associated with the industry. Subject experts should be consulted to devise such a cost effective and easy to follow syllabus and training system. Airline industry has a major role to play in future infections and prevention of global outbreak of local diseases. WHO has released some guidelines about this (https://www.cdc.gov/quarantine/air/managing-sick-travelers/ncovairlines.html). It is also important to have a certification of every airline company by aviation authorities for their efficacy in identifying and stopping the spread of any potential infectious threat. The members of the crew should be especially trained for this.

\begin{tabular}{|l|l|l|l|}
\hline S. No & Query & $\begin{array}{l}\text { True/False } \\
\text { (Yes/No) }\end{array}$ & Explanation \\
\hline 1 & $\begin{array}{l}\text { Can SARS-Cov-2 be transmitted in areas } \\
\text { with hot and humid climates? }\end{array}$ & Yes & $\begin{array}{l}\text { As far as the current evidence is concerned, the SARS-Cov-2 has } \\
\text { the ability of transmission in all areas and in hot and humid } \\
\text { weather also. }\end{array}$ \\
\hline 2 & $\begin{array}{l}\text { Can cold weather and/or snow kill } \\
\text { coronavirus }\end{array}$ & No & $\begin{array}{l}\text { There seems to be no reason to believe that cold weather can } \\
\text { neutralize coronaviruses. Humans are homeotherms and their } \\
\text { body temperature is maintained around 36 degree Celsius to 37 } \\
\text { degree Celsius. So, the weather and external temperature may } \\
\text { not be that important. }\end{array}$ \\
\hline 3 & $\begin{array}{l}\text { Does taking hot baths or cold baths } \\
\text { prevent the new coronavirus disease? }\end{array}$ & No & $\begin{array}{l}\text { Taking hot/cold baths does not prevent from catching COVID- } \\
\text { recause our body temperature remains fairly same } \\
\text { throughout. And also, there is no reason to believe that will be }\end{array}$ \\
\hline
\end{tabular}




\begin{tabular}{|c|c|c|c|}
\hline & & & $\begin{array}{l}\text { neutralized at the temperatures of the water that we use for taking } \\
\text { baths. }\end{array}$ \\
\hline 4 & $\begin{array}{l}\text { Does coronavirus get transmitted through } \\
\text { mosquito bites? }\end{array}$ & No & $\begin{array}{l}\text { Coronavirus infection is not transmitted through mosquito bites. } \\
\text { It is to be understood that coronavirus is a respiratory virus and } \\
\text { hence is mostly spread through contact (direct as well as indirect) } \\
\text { and droplets }\end{array}$ \\
\hline 5 & Can hand dryers kill SARS-Cov-2? & No & $\begin{array}{l}\text { Washing hands frequently with soap is helpful preventing } \\
\text { SARS-Cov-2 infection. But hand dryers may not be helpful. }\end{array}$ \\
\hline 6 & 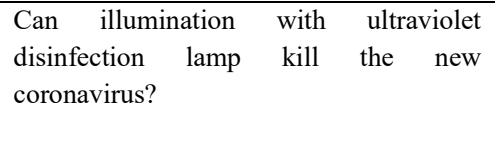 & $\begin{array}{l}\text { UV lamps should } \\
\text { not be used on any } \\
\text { part of the body for } \\
\text { disinfection }\end{array}$ & $\begin{array}{l}\text { UV radiations are harmful and therefore the use of UV lamps to } \\
\text { disinfect any part of body might prove to be harmful and ever } \\
\text { fatal. }\end{array}$ \\
\hline 7 & $\begin{array}{l}\text { Can thermal scanners detect/diagnose new } \\
\text { coronavirus infection? }\end{array}$ & No & $\begin{array}{l}\text { Thermal scanners are designed to measure body temperature. } \\
\text { Since fever is one of the presenting symptoms of COVID-19, } \\
\text { thermal scanners do help in knowing if the patient has fever but } \\
\text { it is not diagnostic for COVID-19. But these scanners do help in } 9 \\
\text { arriving at the diagnosis. }\end{array}$ \\
\hline 8 & $\begin{array}{l}\text { Can spraying alcohol or chlorine all over } \\
\text { your body kill the new coronavirus? }\end{array}$ & No & $\begin{array}{l}\text { Spraying disinfectant may kill the viruses that are on your body } \\
\text { surface but they cannot kill the viruses that have already entered } \\
\text { your body. Moreover, spraying such substances all over your } \\
\text { body can be harmful. Disinfectants should be used in proper } \\
\text { quantities with proper recommendations. }\end{array}$ \\
\hline 9 & $\begin{array}{l}\text { If COVID-19 leads to pneumonia can } \\
\text { vaccine against pneumonia protect against } \\
\text { the new coronavirus? }\end{array}$ & No & $\begin{array}{l}\text { SARS-Cov- } 2 \text { is a new virus and needs its own vaccine. Vaccines } \\
\text { against pneumonia and influenza, do not give protection against } \\
\text { the new coronavirus. }\end{array}$ \\
\hline 10 & $\begin{array}{l}\text { Can rinsing the nose regularly with saline } \\
\text { water help in preventing the new } \\
\text { coronavirus infection? }\end{array}$ & No & $\begin{array}{l}\text { Though there is some evidence that rinsing nose with saline } \\
\text { water may help to recover from common cold but there is no } \\
\text { evidence of any protection by this practice against COVID- } 19 \text {. }\end{array}$ \\
\hline \multirow[t]{2}{*}{11} & $\begin{array}{l}\text { Can eating garlic and/or onion prevent } \\
\text { getting infected with the new coronavirus? }\end{array}$ & No & $\begin{array}{l}\text { There is no evidence that suggests any protective effects of } \\
\text { ginger, garlic or onion against COVID-19 infection. }\end{array}$ \\
\hline & Does new coronavirus infect elderly only? & No & $\begin{array}{l}\text { SARS-Cov- } 2 \text { infects people of all ages and genders, however, } \\
\text { people with advanced age and other comorbid medical } \\
\text { conditions (like tuberculosis, asthma, diabetes etc.) develop } \\
\text { complications more often. }\end{array}$ \\
\hline 12 & $\begin{array}{l}\text { Can antibiotics effective in preventing and } \\
\text { treating the new coronavirus? }\end{array}$ & No & $\begin{array}{l}\text { Antibiotics are not effective in prevention and/or treatment of } \\
\text { COVID-19 because it is a viral infection. However, patients may } \\
\text { receive antibiotic treatment to prevent or treat any parallel } \\
\text { bacterial infections. }\end{array}$ \\
\hline 13 & $\begin{array}{l}\text { Are there any drugs available to prevent or } \\
\text { treat the new coronavirus? }\end{array}$ & No & $\begin{array}{l}\text { As of now, there is not drug or vaccine available to treat COVID- } \\
19 \text { but certain medications are being tried to manage the } \\
\text { symptoms like fever. }\end{array}$ \\
\hline 14 & Do I need to wear a mask if I am healthy? & Not necessarily & $\begin{array}{l}\text { It is recommended to wear a mask if a person is ill or is taking } \\
\text { care of a person suffering from COVID-19 or suspected of } \\
\text { SARS-Cov- } 2 \text { infection. }\end{array}$ \\
\hline 15 & $\begin{array}{l}\text { Do I need to wear a mask if I am coughing } \\
\text { or sneezing }\end{array}$ & Yes & $\begin{array}{l}\text { It is always better to wear a mask in coughing and sneezing. This } \\
\text { prevent the spread of droplets. }\end{array}$ \\
\hline 16 & $\begin{array}{l}\text { Is wearing a mask enough to keep stay safe } \\
\text { from SARS-Cov-2 infection? }\end{array}$ & No & $\begin{array}{l}\text { Wearing a mask is better as it prevents the droplet infection and } \\
\text { some masks even neutralize the virus but it should be } \\
\text { accompanied with observance of standard operating procedures } \\
\text { and recommendation (like regular washing of hands etc.) to be } \\
\text { effective. }\end{array}$ \\
\hline 17 & $\begin{array}{l}\text { Can we throw away the mask anywhere } \\
\text { after use? }\end{array}$ & No & $\begin{array}{l}\text { Masks should be disposed off properly and in proper bins. } \\
\text { Throwing away the mask anywhere may be a source of infection } \\
\text { spread. }\end{array}$ \\
\hline
\end{tabular}




\begin{tabular}{|c|c|c|c|}
\hline 18 & $\begin{array}{l}\text { Can any mask be used to prevent COVID- } \\
19 ?\end{array}$ & No & $\begin{array}{l}\text { Though all masks are effective in stopping the droplets but all } \\
\text { masks do not neutralize the virus. So, it is important to use } \\
\text { special masks that can neutralize the virus in order to stay safe } \\
\text { from COVID-19 }\end{array}$ \\
\hline 19 & $\begin{array}{l}\text { Is a vaccine to cure or prevent COVID-19 } \\
\text { available? }\end{array}$ & No & $\begin{array}{l}\text { There is, as of now, no vaccine available for prevention and no } \\
\text { medicine available for treatment of COVID-19. Initial studies } \\
\text { have started all over the world no laboratory or research group } \\
\text { has yet been successful. }\end{array}$ \\
\hline 20 & $\begin{array}{l}\text { Can a person stay protected from SARS- } \\
\text { Cov-2 by swallowing or gargling bleach, } \\
\text { or taking acetic acid or steroids, or using } \\
\text { essential oils, saline water, or any other } \\
\text { substance? }\end{array}$ & No & $\begin{array}{l}\text { There is no evidence that these practices help to prevent or treat } \\
\text { COVID-19. On the contrary, such practices may prove to be } \\
\text { harmful. }\end{array}$ \\
\hline 21 & $\begin{array}{l}\text { Was new coronavirus actually deliberately } \\
\text { created or released by some people to } \\
\text { infect masses? }\end{array}$ & No & $\begin{array}{l}\text { Viruses can change over time and outbreak occur when the virus } \\
\text { acquires the ability to infect humans and also has human to } \\
\text { human transmission ability. }\end{array}$ \\
\hline 22 & $\begin{array}{l}\text { Can ordering or buying products that are } \\
\text { shipped from China infect a person with } \\
\text { COVID-19? }\end{array}$ & No & $\begin{array}{l}\text { Coronaviruses do not stay alive for very long on surfaces. So, it } \\
\text { is not likely that a person gets infection from a package which } \\
\text { was already on transit for weeks. The most frequent route of } \\
\text { transmission is through droplet infection. }\end{array}$ \\
\hline
\end{tabular}

Table 3: This table aims at busting the myths that have been surrounding the COVID-19 pandemic due to momentous misinformation and confusion. This table is a comprehensive list of questions and their most likely answers in terms of the latest literature. These answers might change as and when the situation evolves. These answers may not be final but they provide a sufficient guide and starting pint of education and myth busting. This table gives most likely answers to doubts and might serve as a 'Frequently Asked Questions' source yet it is advisable to look into the latest peer reviewed literature to get up to date information.

In the light of the present scenario, very little is known about SARSCoV-2 and its consequent disease COVID-19 but there is optimism of having this pandemic being controlled if proper measures are taken. This pandemic is a whistleblower of the future potential pandemics which also might originate from nocturnal mammals as primary as well as intermediate hosts. To this effect, governments have to be ready with trained medical care and pertinent personnel. In fact, kids in schools also need to be trained about different ways to quarantine and about ways to help in such situations.

While the COVID-19 pandemic has brought life to a halt globally, this does not seem to be the status quo for long-term future (Petropoulos \& Makridakis, 2020; Santacrose et al., 2020; Prompetchara et al., 2020). Many speculations have already been made as to how to end this pandemic (Guest et al., 2020; Peto et al., 2020). Given the $\mathrm{R}_{0}$ (3.7) and SI (7.5 days) values of the virus along with the timeline of recovery (and the proportions thereof), the time-course of vaccines development and improved management strategies; it appears that COVID-19 might follow one of the two patterns with regards to its pathogenic interaction with humans. One is that the infection will eventually pacify and we might not see more cases once the pandemic is over and no active case is reported. The second path is that SARS-CoV-2 becomes a regular part of human viral pathogen repertoire and we may either have to vaccinate our population on regular basis (like flu shots) or once in a life time (a rare possibility). In any case, it might take a year or two for the pandemic to subside to levels that warrant a complete return of normal life. The optimism that the pandemic will die down in a matter of two to three months is not a realistic outlook, nevertheless. Since very little is known about SARS-CoV-2 and the body's immune response against this virus, it might be early to make sweeping statements and strong predictions about the dynamics of the pandemic. But reasonable guesses by experts should be acknowledged given the fact that the possibility of an outbreak was also indicated through an expert guess at least one year before the onset of COVID-19. In a scenario when a significant proportion of the population contracts the infection, a majority of the infected individuals develops resistance (immunity) against the virus. This immunity may be long-lived or may reduce down in a small period of time. In case of long-term immunity, it will become difficult for the virus to maintain its inter-human transmission and hence the society will eventually recover. This is an ardent possibility but there is no way as of now to know the timeline of such a scenario. It appears that either a vaccine will be developed and we may achieve population level immunity (or what we refer to as herd immunity) or the virus infects (and in the process kills) a significant number of people thereby rendering those who recover as immune. The caveat here is that it is too early to claim that those recovering from COVID-19 are immune to SARS-CoV-2. With regards to the timeline the harmonogram appears to be a year or two long. While in the meantime slowly and steadily life will return back to normalcy. 
It might be a critical challenge to people, experts and regulatory bodies to know when, how and to what extent will it be appropriate to restore various institutions in the society. It may be a good idea to carry out this return to normalcy operation in phases. Simulation studies on the unfreezing dynamics of the restricted life have to be carried out which might help in making a safe return otherwise there is a consistent threat of resurgence of the disease in addition to the upsurge of psychiatric issues. In the first phase, it might be safe and to initially experiment with letting the offices and restaurants open but enforcing the maintenance of social distancing by keeping serving tables and workstations far apart. Crowd control strategies, guidelines, instructions and ready availability of sanitizers has to be an ardent part of these places. It might not be a good idea to start music festivals, religious congregations and other crowd building events in the first phases. Also, authorities should consider the work from home option for the period long enough to be sure about the safety. The present scenario may serve as a prelude for the possible "work from home" scenario. If a substantial number of people can work from home, it may help in bringing down the severity of urban chaos thereby preventing the rampant spread of various infections. In addition, vehicular traffic and noise pollution can also pacify which may in turn be a good sign for the global warming issue. While offices might be opened in initial phases (whenever the public health experts unanimously deem suitable) as restaurants but public parks and beach gathering may not be a part of this list and restrictions should be imposed for relatively longer periods of time. While different phases of normal life may eventually be restored, public health experts, healthcare associations and governments need to keep a strong vigil and be prepared for a relapse anytime. The preparedness has to be from public education, improvement in personal hygiene, availability of sufficient and good quality personal protective equipment to hospital beds, makeshift hospitals and availability of ventilators, medication and vaccines. Such a preparedness should not be restricted to COVID-19 but all the future strategies warrant such a readiness because of the modern cosmopolitan lifestyle; many other pandemics might be awaiting us in near future. In terms of restoration of air travel, the good news is that the circulated air within the aircraft is filtered and most of the pathogens are cleared but the staff may need to be well trained to identify potentially dangerous infections or individuals at high risk of contracting infections. Hence, relevant guidelines may need to be developed to address these issues. In the light of all these dimensions, a fewmonth timeline for return to normalcy does not seem to be a probable eventuality. At the same time, we don't know what is the actual molecular scenario and our immune conglomeration against the virus so statements like these should be taken with caution. There is every chance that most of what we know about SARS-
CoV-2 (and COVID-19) may change rapidly as the situation evolves and new information comes to limelight.

Developing vaccines may be quick but perfecting vaccines for such infections is extremely difficult. And in situations like COVID-19 where everyone is waiting for a vaccine desperately, it is possible that certain downsides or harmful effects of a potential vaccine (or treatment regimen) might be overlooked and that might itself present as a hazard immediately or in the long run. Vaccination of hundreds of millions of people seems to be extremely difficult task at the outset and WHO has a momentous task ahead to this effect. World charities need to come forward to raise funds for WHO so that unanimous and authentic body of experts take care of threats like this. Also, availability if subsidized vaccines (or cost-effective vaccines) is another issue that we may be facing in a few months from now. In the light of this, it appears that return of the normal life does not seem to be plausible at least for a few months from now. Onset of summer may or may not bring down the infection rates. Even if the pandemic pacifies significantly, public health experts, governments, healthcare establishments and general public have to be cautious about the resurgence and authorities would have to consider reopening every institution in phases with comprehensive deliberation on expert recommendations.

\section{Conclusion}

COVID-19 has been declared a pandemic by WHO and it is spreading very fast. This pandemic has impacted many areas of human health and has led to crisis in the medical management worldwide. It appears that the virus mediates its pathogenic effects through binding with ACE-2. In certain cases, the infection turns out to be fata (particularly in elderly and those with comorbid conditions). While the virus has high infectivity, the infection can be avoided and hence the spread can be halted. With increasing number of deaths, rigorous research studies are being conducted to get insights into this disease and to develop vaccine and effective treatment regimens. Diagnostic kits are also being developed but have not yet been distributed widely. Even there has been an acute shortage of personal protective equipment (like face masks) worldwide. This has given us an idea about the preparedness of human all over the globe for pandemics like this. Additionally, a lot of misinformation is being spread about COVID-19 which has led to panic. In a world where we have guidelines in place to meet even aliens, this pandemic is a reminder of our humble preparedness towards any global pandemic that might occur in future. Therefore, recommendations should be developed and guidelines issued with international cooperation to curb this disease and the pandemics that we are likely to face in near future.

\section{Conflict of Interest}


All the authors declare "No Conflict of Interest"

\section{Author Contributions}

MAF, AK and HNS conceived the idea. MAF and AK wrote the first draft, MAF, AK, HNS, VP, KRM, SNP, RKN, MK and CK revised the draft. MAF, AK, HNS, VP, KRM, SNP, RKN, MK and CK contributed to Table preparation. HN, MAF and AK prepared the figures.

\section{Funding}

There was no dedicated funding for this project.

\section{Acknowledgments}

The authors wish the acknowledge Johns Hopkins University \& Medicine, Coronavirus Resource Center and World health Organization for ready availability of data in the public domain

\section{References:}

Ahlquist, P., Noueiry, A. O., Lee, W. M., Kushner, D. B., \& Dye, B. T. (2003). Host factors in positive-strand RNA virus genome replication. J Virol, 77(15), 8181-8186. doi:10.1128/jvi.77.15.8181-8186.2003

Ahmed, S. F., Quadeer, A. A., \& McKay, M. R. (2020). Preliminary Identification of Potential Vaccine Targets for the COVID-19 Coronavirus (SARS-CoV-2) Based on SARS-CoV Immunological Studies. Viruses, 12(3). doi:10.3390/v12030254 Ai, T., Yang, Z., Hou, H., Zhan, C., Chen, C., Lv, W., . . Xia, L. (2020). Correlation of Chest CT and RT-PCR Testing in Coronavirus Disease 2019 (COVID-19) in China: A Report of 1014 Cases. Radiology, 200642. doi:10.1148/radiol.2020200642

Aitken, C., \& Jeffries, D. J. (2001). Nosocomial spread of viral disease. Clin Microbiol Rev, 14(3), 528-546. doi:10.1128/CMR.14.3.528-546.2001

Al Awaidy, S. T., \& Khamis, F. (2019). Middle East Respiratory Syndrome Coronavirus (MERS-CoV) in Oman: Current Situation and Going Forward. Oman Med J, 34(3), 181-183. doi:10.5001/omj.2019.36

Al-Tawfiq, J. A., Al-Homoud, A. H., \& Memish, Z. A. (2020). Remdesivir as a possible therapeutic option for the COVID-19. Travel Med Infect Dis, 101615. doi:10.1016/j.tmaid.2020.101615

Alsolamy, S., \& Arabi, Y. M. (2015). Infection with Middle East respiratory syndrome coronavirus. Can J Respir Ther, 51(4), 102

Ameli, J. (2015). Communicable Diseases and Outbreak Control. Turk J Emerg Med, 15(Suppl 1), 20-26. doi:10.5505/1304.7361.2015.19970

Anderson, R. M., Heesterbeek, H., Klinkenberg, D., \& Hollingsworth, T. D. (2020). How will country-based mitigation measures influence the course of the COVID-19 epidemic? Lancet, 395(10228), 931-934. doi:10.1016/S01406736(20)30567-5

Atkins, K. E., Wenzel, N. S., Ndeffo-Mbah, M., Altice, F. L., Townsend, J. P., \& Galvani, A. P. (2015). Under-reporting and case fatality estimates for emerging epidemics. BMJ, 350, h1115. doi:10.1136/bmj.h1115
Bai, H. X., Hsieh, B., Xiong, Z., Halsey, K., Choi, J. W., Tran, T. M. L., . . Liao, W. H. (2020). Performance of radiologists in differentiating COVID-19 from vira pneumonia on chest CT. Radiology, 200823. doi:10.1148/radiol.2020200823 Banerjee, A., Kulcsar, K., Misra, V., Frieman, M., \& Mossman, K. (2019). Bats and Coronaviruses. Viruses, 11(1). doi:10.3390/v11010041

Barry, M., Al Amri, M., \& Memish, Z. A. (2020). COVID-19 in the Shadows of MERS-CoV in the Kingdom of Saudi Arabia. J Epidemiol Glob Health, 10(1), 13. doi:10.2991/jegh.k.200218.003

Bhatia, P. K., Sethi, P., Gupta, N., \& Biyani, G. (2016). Middle East respiratory syndrome: A new global threat. Indian J Anaesth, 60(2), 85-88. doi:10.4103/00195049.176286

Biggerstaff, M., Cauchemez, S., Reed, C., Gambhir, M., \& Finelli, L. (2014) Estimates of the reproduction number for seasonal, pandemic, and zoonotic influenza: a systematic review of the literature. BMC Infect Dis, 14, 480 doi:10.1186/1471-2334-14-480

Bolles, M., Donaldson, E., \& Baric, R. (2011). SARS-CoV and emergent coronaviruses: viral determinants of interspecies transmission. Curr Opin Virol, 1(6), 624-634. doi:10.1016/j.coviro.2011.10.012

Bordi, L., Nicastri, E., Scorzolini, L., Di Caro, A., Capobianchi, M. R., Castilletti, C., . . . Collaborating, C. (2020). Differential diagnosis of illness in patients under investigation for the novel coronavirus (SARS-CoV-2), Italy, February 2020. Euro Surveill, 25(8). doi:10.2807/1560-7917.ES.2020.25.8.2000170

Buonsenso, D., Pata, D., \& Chiaretti, A. (2020). COVID-19 outbreak: less stethoscope, more ultrasound. Lancet Respir Med. doi:10.1016/S22132600(20)30120-X

Buonsenso, D., Piano, A., Raffaelli, F., Bonadia, N., de Gaetano Donati, K., \& Franceschi, F. (2020). Point-of-Care Lung Ultrasound findings in novel coronavirus disease-19 pnemoniae: a case report and potential applications during COVID-19 outbreak. Eur Rev Med Pharmacol Sci, 24(5), 2776-2780. doi:10.26355/eurrev_202003_20549

Cai J, Sun W, Huang J, Gamber M, Wu J, He G. Indirect virus transmission in cluster of COVID-19 cases, Wenzhou, China, 2020. Emerg Infect Dis. 2020 Jun [date cited]. https://doi.org/10.3201/eid2606.200412

Cameron, C. E., Moustafa, I. M., \& Arnold, J. J. (2016). Fidelity of Nucleotide Incorporation by the RNA-Dependent RNA Polymerase from Poliovirus Enzymes, 39, 293-323. doi:10.1016/bs.enz.2016.02.002 Cao, B., Wang, Y., Wen, D., Liu, W., Wang, J., Fan, G., . . Wang, C. (2020). A Trial of Lopinavir-Ritonavir in Adults Hospitalized with Severe Covid-19. N Eng J Med. doi:10.1056/NEJMoa2001282

Cascella, M., Rajnik, M., Cuomo, A., Dulebohn, S. C., \& Di Napoli, R. (2020) Features, Evaluation and Treatment Coronavirus (COVID-19). In StatPearls Treasure Island (FL)

Chan-Yeung, M., \& Xu, R. H. (2003). SARS: epidemiology. Respirology, 8 Suppl, S9-14. doi:10.1046/j.1440-1843.2003.00518.x

Chan, J. F., Lau, S. K., To, K. K., Cheng, V. C., Woo, P. C., \& Yuen, K. Y. (2015) Middle East respiratory syndrome coronavirus: another zoonotic betacoronavirus causing SARS-like disease. Clin Microbiol Rev, 28(2), 465-522. doi:10.1128/CMR.00102-14 
Chan, J. F., Yip, C. C., To, K. K., Tang, T. H., Wong, S. C., Leung, K. H., . . . Yuen, K. Y. (2020). Improved molecular diagnosis of COVID-19 by the novel, highly sensitive and specific COVID-19-RdRp/Hel real-time reverse transcriptionpolymerase chain reaction assay validated in vitro and with clinical specimens. $\mathrm{J}$ Clin Microbiol. doi:10.1128/JCM.00310-20

Chan, J. F., Yuan, S., Kok, K. H., To, K. K., Chu, H., Yang, J., . . Yuen, K. Y. (2020). A familial cluster of pneumonia associated with the 2019 novel coronavirus indicating person-to-person transmission: a study of a family cluster. Lancet, 395(10223), 514-523. doi:10.1016/S0140-6736(20)30154-9

Chan, P. K., \& Chan, M. C. (2013). Tracing the SARS-coronavirus. J Thorac Dis, 5 Suppl 2, S118-121. doi:10.3978/j.issn.2072-1439.2013.06.19

Chen H, Guo J, Wang C, Luo F, Yu X, Zhang W, et al. Clinical characteristics and intrauterine vertical transmission potential of COVID-19 infection in nine pregnant women: a retrospective review of medical records. Lancet. 2020 Mar 7;395(10226):809-15.

Chen, D., Xu, W., Lei, Z., Huang, Z., Liu, J., Gao, Z., \& Peng, L. (2020). Recurrence of positive SARS-CoV-2 RNA in COVID-19: A case report. Int J Infect Dis, 93, 297-299. doi:10.1016/j.ijid.2020.03.003

Chen, X., \& Yu, B. (2020). First two months of the 2019 Coronavirus Disease (COVID-19) epidemic in China: real-time surveillance and evaluation with a second derivative model. Glob Health Res Policy, 5, 7. doi:10.1186/s41256-020$00137-4$

Cheng, H., Wang, Y., \& Wang, G. Q. (2020). Organ-protective Effect of Angiotensin-converting Enzyme 2 and its Effect on the Prognosis of COVID-19. J Med Virol. doi:10.1002/jmv.25785

Cheng, Z., Lu, Y., Cao, Q., Qin, L., Pan, Z., Yan, F., \& Yang, W. (2020). Clinical Features and Chest CT Manifestations of Coronavirus Disease 2019 (COVID-19) in a Single-Center Study in Shanghai, China. AJR Am J Roentgenol, 1-6. doi: 10.2214/AJR.20.22959

Choi, S. C., \& Ki, M. (2020). Estimating the reproductive number and the outbreak size of Novel Coronavirus disease (COVID-19) using mathematical model in Republic of Korea. Epidemiol Health, e2020011. doi:10.4178/epih.e2020011

Cleri, D. J., Ricketti, A. J., \& Vernaleo, J. R. (2010). Severe acute respiratory syndrome (SARS). Infect Dis Clin North Am, 24(1), 175-202. doi:10.1016/j.idc.2009.10.005

Cowling, B. J., Fang, V. J., Riley, S., Malik Peiris, J. S., \& Leung, G. M. (2009). Estimation of the serial interval of influenza. Epidemiology, 20(3), 344-347. doi:10.1097/EDE.0b013e31819d1092

Craig, A. T., Heywood, A. E., \& Hall, J. (2020). Risk of COVID-19 importation to the Pacific islands through global air travel. Epidemiol Infect, 1-16. doi: $10.1017 /$ S0950268820000710

Cucinotta, D., \& Vanelli, M. (2020). WHO Declares COVID-19 a Pandemic. Acta Biomed, 91(1), 157-160. doi:10.23750/abm.v91i1.9397

Dai, W. C., Zhang, H. W., Yu, J., Xu, H. J., Chen, H., Luo, S. P., . . Lin, F. (2020). CT Imaging and Differential Diagnosis of COVID-19. Can Assoc Radiol J, 846537120913033. doi:10.1177/0846537120913033

Darnell, M. E., Subbarao, K., Feinstone, S. M., \& Taylor, D. R. (2004). Inactivation of the coronavirus that induces severe acute respiratory syndrome, SARS-CoV. J Virol Methods, 121(1), 85-91. doi:10.1016/j.jviromet.2004.06.006
Dawson, P., Malik, M. R., Parvez, F., \& Morse, S. S. (2019). What Have We Learned About Middle East Respiratory Syndrome Coronavirus Emergence in Humans? A Systematic Literature Review. Vector Borne Zoonotic Dis, 19(3), 174192. doi: $10.1089 / \mathrm{vbz} .2017 .2191$

de Almeida, M. A. (2013). Epidemics in the news: Health and hygiene in the press in periods of crisis. Public Underst Sci, 22(7), 886-902. doi: $10.1177 / 0963662512473212$

Deng, Y., Tan, X., Li, M. L., Wang, W. Z., \& Wang, Y. K. (2019). AngiotensinConverting Enzyme 2 in the Rostral Ventrolateral Medulla Regulates Cholinergic Signaling and Cardiovascular and Sympathetic Responses in Hypertensive Rats. Neurosci Bull, 35(1), 67-78. doi:10.1007/s12264-018-0298-3

de Wit, E., van Doremalen, N., Falzarano, D., \& Munster, V. J. (2016). SARS and MERS: recent insights into emerging coronaviruses. Nat Rev Microbiol, 14(8), 523-534. doi:10.1038/nrmicro.2016.81

Delamater, P. L., Street, E. J., Leslie, T. F., Yang, Y. T., \& Jacobsen, K. H. (2019) Complexity of the Basic Reproduction Number (R0). Emerg Infect Dis, 25(1), 14. doi:10.3201/eid2501.171901

Denison, M. R., Graham, R. L., Donaldson, E. F., Eckerle, L. D., \& Baric, R. S. (2011). Coronaviruses: an RNA proofreading machine regulates replication fidelity and diversity. RNA Biol, 8(2), 270-279. doi:10.4161/rna.8.2.15013

Dietz, K. (1993). The estimation of the basic reproduction number for infectious diseases. Stat Methods Med Res, 2(1), 23-41. doi:10.1177/096228029300200103 Dombrovskiy, V. Y., Martin, A. A., Sunderram, J., \& Paz, H. L. (2005). Facing the challenge: decreasing case fatality rates in severe sepsis despite increasing hospitalizations. Crit Care Med, 33(11), 2555-2562. doi:10.1097/01.ccm.0000186748.64438.7b

Dong, L., Hu, S., \& Gao, J. (2020). Discovering drugs to treat coronavirus disease 2019 (COVID-19). Drug Discov Ther, 14(1), 58-60. doi:10.5582/ddt.2020.01012 Dong, X. C., Li, J. M., Bai, J. Y., Liu, Z. Q., Zhou, P. H., Gao, L., . . Zhang, Y. (2020). [Epidemiological characteristics of confirmed COVID-19 cases in Tianjin]. Zhonghua Liu Xing Bing Xue Za Zhi, 41(5), 638-642. doi:10.3760/cma.j.cn112338-20200221-00146

Donnelly, C. A., Finelli, L., Cauchemez, S., Olsen, S. J., Doshi, S., Jackson, M. L., , . p, H. N. H. I. W. G. (2011). Serial intervals and the temporal distribution of secondary infections within households of 2009 pandemic influenza A (H1N1): implications for influenza control recommendations. Clin Infect Dis, 52 Suppl 1, S123-130. doi:10.1093/cid/ciq028

Driscoll, K. E., Maurer, J. K., Higgins, J., \& Poynter, J. (1995). Alveolar macrophage cytokine and growth factor production in a rat model of crocidoliteinduced pulmonary inflammation and fibrosis. J Toxicol Environ Health, 46(2), 155-169. doi:10.1080/15287399509532026

Du, Z., Xu, X., Wu, Y., Wang, L., Cowling, B. J., \& Meyers, L. A. (2020). Serial Interval of COVID-19 among Publicly Reported Confirmed Cases. Emerg Infect Dis, 26(6). doi:10.3201/eid2606.200357

Duan, S. M., Zhao, X. S., Wen, R. F., Huang, J. J., Pi, G. H., Zhang, S. X., . . Team, S. R. (2003). Stability of SARS coronavirus in human specimens and environment and its sensitivity to heating and UV irradiation. Biomed Environ Sci, 16(3), 246-255. 
Duguid, J. P. (1946). The size and the duration of air-carriage of respiratory droplets and droplet-nuclei. J Hyg (Lond), 44(6), 471-479. doi: $10.1017 / \mathrm{s} 0022172400019288$

Elena S.F., Sanjuan R. Adaptive value of high mutation rates of RNA viruses: Separating causes from consequences. J. Virol. 2005;79:11555-11558. doi: 10.1128/JVI.79.18.11555-11558.2005.

Elfiky, A. A. (2020). Ribavirin, Remdesivir, Sofosbuvir, Galidesivir, and Tenofovir against SARS-CoV-2 RNA dependent RNA polymerase (RdRp): A molecular docking study. Life Sci, 117592. doi:10.1016/j.1fs.2020.117592

Erdem, H., \& Unal, S. (2015). New global viral threats. Saudi Med J, 36(4), 393 398. doi:10.15537/smj.2015.4.10089

Faiq, M. A., Kumar, A., Singh, H. N., Pareek, V., \& Kumar, P. (2018). Commentary: A Possible Mechanism of Zika Virus Associated Microcephaly: Imperative Role of Retinoic Acid Response Element (RARE) Consensus Sequence Repeats in the Viral Genome. Front Microbiol, 9, 190. doi: $10.3389 /$ fmicb. 2018.00190

Fang, Y., Zhang, H., Xie, J., Lin, M., Ying, L., Pang, P., \& Ji, W. (2020). Sensitivity of Chest CT for COVID-19: Comparison to RT-PCR. Radiology, 200432. doi:10.1148/radiol.2020200432

Fehr, A. R., \& Perlman, S. (2015). Coronaviruses: an overview of their replication and pathogenesis. Methods Mol Biol, 1282, 1-23. doi:10.1007/978-1-4939-2438$7+1$

Fehr, A. R., Channappanavar, R., \& Perlman, S. (2017). Middle East Respiratory Syndrome: Emergence of a Pathogenic Human Coronavirus. Annu Rev Med, 68, 387-399. doi:10.1146/annurev-med-051215-031152

Fernstrom, A., \& Goldblatt, M. (2013). Aerobiology and its role in the transmission of infectious diseases. J Pathog, 2013, 493960. doi:10.1155/2013/493960

Fisher, D., \& Heymann, D. (2020). Q\&A: The novel coronavirus outbreak causing COVID-19. BMC Med, 18(1), 57. doi:10.1186/s12916-020-01533-w

Freeman, A. M., \& Leigh, J. T. R. (2020). Viral Pneumonia. In StatPearls. Treasure Island (FL).

Frieden, T. R., \& Lee, C. T. (2020). Identifying and Interrupting Superspreading Events-Implications for Control of Severe Acute Respiratory Syndrome Coronavirus 2. Emerg Infect Dis, 26(6). doi:10.3201/eid2606.200495 Gao, J. W., Rizzo, S., Ma, L. H., Qiu, X. Y., Warth, A., Seki, N., . . . written on behalf of the, A. M. E. L. C. C. G. (2017). Pulmonary ground-glass opacity: computed tomography features, histopathology and molecular pathology. Transl Lung Cancer Res, 6(1), 68-75. doi:10.21037/tlcr.2017.01.02

Geldsetzer, P. (2020). Knowledge and Perceptions of COVID-19 Among the General Public in the United States and the United Kingdom: A Cross-sectional Online Survey. Ann Intern Med. doi:10.7326/M20-0912

Goldenthal, K. L., Midthun, K., \& Zoon, K. C. (1996). Control of Viral Infections and Diseases. In th \& S. Baron (Eds.), Medical Microbiology. Galveston (TX).

Gordon, C. J., Tchesnokov, E. P., Feng, J. Y., Porter, D. P., \& Gotte, M. (2020). The antiviral compound remdesivir potently inhibits RNA-dependent RNA polymerase from Middle East respiratory syndrome coronavirus. J Biol Chem. doi:10.1074/jbc.AC120.013056

Gralinski, L. E., \& Baric, R. S. (2015). Molecular pathology of emerging coronavirus infections. J Pathol, 235(2), 185-195. doi:10.1002/path.4454
Greatorex, J. S., Digard, P., Curran, M. D., Moynihan, R., Wensley, H., Wreghitt, T., ... Nguyen-Van-Tam, J. S. (2011). Survival of influenza A(H1N1) on materials found in households: implications for infection control. PLoS One, 6(11), e27932. doi:10.1371/journal.pone.0027932

Gu, J., Han, B., \& Wang, J. (2020). COVID-19: Gastrointestinal manifestations and potential fecal-oral transmission. Gastroenterology. doi:10.1053/j.gastro.2020.02.054

Guan WJ, Ni ZY, Hu Y, Liang WH, Ou CQ, He JX, et al. Clinical Characteristics of Coronavirus Disease 2019 in China. N Engl J Med. 2020 Feb 28.

Guest, J. L., Del Rio, C., \& Sanchez, T. (2020). The 3 Steps Needed to End the COVID-19 Pandemic: Bold Public Health Leadership, Rapid Innovations, and Courageous Political Will. JMIR Public Health Surveill. doi:10.2196/19043 Guo, Y. R., Cao, Q. D., Hong, Z. S., Tan, Y. Y., Chen, S. D., Jin, H. J., . . Yan, Y. (2020). The origin, transmission and clinical therapies on coronavirus disease 2019 (COVID-19) outbreak - an update on the status. Mil Med Res, 7(1), 11 doi:10.1186/s40779-020-00240-0

Hajjar, S. A., Memish, Z. A., \& McIntosh, K. (2013). Middle East Respiratory Syndrome Coronavirus (MERS-CoV): a perpetual challenge. Ann Saudi Med, 33(5), 427-436. doi:10.5144/0256-4947.2013.427

Hamming, I., Cooper, M. E., Haagmans, B. L., Hooper, N. M., Korstanje, R., Osterhaus, A. D., . . . van Goor, H. (2007). The emerging role of ACE2 in physiology and disease. J Pathol, 212(1), 1-11. doi:10.1002/path.2162 Hamming, I., Timens, W., Bulthuis, M. L. C., Lely, A. T., Navis, G. J., \& van Goor, H. (2004). Tissue distribution of ACE2 protein, the functional receptor for SARS coronavirus. A first step in understanding SARS pathogenesis. The Journal of Pathology: A Journal of the Pathological Society of Great Britain and Ireland, 203(2), 631-637.

Han, Y., \& Yang, H. (2020). The transmission and diagnosis of 2019 novel coronavirus infection disease (COVID-19): A Chinese perspective. J Med Virol doi: $10.1002 /$ jmv. 25749

Hashimoto, T., Perlot, T., Rehman, A., Trichereau, J., Ishiguro, H., Paolino, M., .. \& Wild, B. (2012). ACE2 links amino acid malnutrition to microbial ecology and intestinal inflammation. Nature, 487(7408), 477-481.

He, F., Deng, Y., \& Li, W. (2020). Coronavirus disease 2019: What we know? J Med Virol. doi:10.1002/jmv.25766

Heffernan, J. M., Smith, R. J., \& Wahl, L. M. (2005). Perspectives on the basic reproductive ratio. J R Soc Interface, 2(4), 281-293. doi:10.1098/rsif.2005.0042 Helewski, K., \& Konecki, J. (1989). [Alveolar cells type II, their role in the biosynthesis of pulmonary surfactant and other functions]. Pol Tyg Lek, 44(2-3), 58-62.

Hellewell, J., Abbott, S., Gimma, A., Bosse, N. I., Jarvis, C. I., Russell, T. W., , . Eggo, R. M. (2020). Feasibility of controlling COVID-19 outbreaks by isolation of cases and contacts. Lancet Glob Health, 8(4), e488-e496. doi:10.1016/S2214109X(20)30074-7

Herbert, C., Scott, M. M., Scruton, K. H., Keogh, R. P., Yuan, K. C., Hsu, K., .. Kumar, R. K. (2010). Alveolar macrophages stimulate enhanced cytokine production by pulmonary CD4+ T-lymphocytes in an exacerbation of murine chronic asthma. Am J Pathol, 177(4), 1657-1664. doi:10.2353/ajpath.2010.100019 
Hogg, W., \& Huston, P. (2006). Controlling droplet-transmitted respiratory infections: best practices and cost. Can Fam Physician, 52(10), 1229-1232.

Hollander, J. E., \& Carr, B. G. (2020). Virtually Perfect? Telemedicine for Covid19. N Engl J Med. doi:10.1056/NEJMp2003539

Holmes, E. C., \& Rambaut, A. (2004). Viral evolution and the emergence of SARS coronavirus. Philos Trans R Soc Lond B Biol Sci, 359(1447), 1059-1065. doi:10.1098/rstb.2004.1478

Hop, J. W., Rinkel, G. J., Algra, A., \& van Gijn, J. (1997). Case-fatality rates and functional outcome after subarachnoid hemorrhage: a systematic review. Stroke, 28(3), 660-664. doi:10.1161/01.str.28.3.660

Howard, C. R., \& Fletcher, N. F. (2012). Emerging virus diseases: can we ever expect the unexpected? Emerg Microbes Infect, 1(12), e46. doi:10.1038/emi.2012.47

Hu, B., Ge, X., Wang, L. F., \& Shi, Z. (2015). Bat origin of human coronaviruses. Virol J, 12, 221. doi:10.1186/s12985-015-0422-1

Huang, C., Wang, Y., Li, X., Ren, L., Zhao, J., Hu, Y., . . Cao, B. (2020). Clinical features of patients infected with 2019 novel coronavirus in Wuhan, China. Lancet, 395(10223), 497-506. doi:10.1016/S0140-6736(20)30183-5

Huber, J. H., Johnston, G. L., Greenhouse, B., Smith, D. L., \& Perkins, T. A. (2016). Quantitative, model-based estimates of variability in the generation and serial intervals of Plasmodium falciparum malaria. Malar J, 15(1), 490 doi:10.1186/s12936-016-1537-6

Huynh, J., Li, S., Yount, B., Smith, A., Sturges, L., Olsen, J. C., . . Donaldson, E. F. (2012). Evidence supporting a zoonotic origin of human coronavirus strain NL63. J Virol, 86(23), 12816-12825. doi:10.1128/JVI.00906-12

Hyodo, K., \& Okuno, T. (2016). Pathogenesis mediated by proviral host factors involved in translation and replication of plant positive-strand RNA viruses. Curr Opin Virol, 17, 11-18. doi:10.1016/j.coviro.2015.11.004

Ibrahim, I. M., Abdelmalek, D. H., Elshahat, M. E., \& Elfiky, A. A. (2020). COVID-19 spike-host cell receptor GRP78 binding site prediction. J Infect. doi:10.1016/j.jinf.2020.02.026

Kakimoto, K., Kamiya, H., Yamagishi, T., Matsui, T., Suzuki, M., \& Wakita, T. (2020). Initial Investigation of Transmission of COVID-19 Among Crew Members During Quarantine of a Cruise Ship - Yokohama, Japan, February 2020. MMWR Morb Mortal Wkly Rep, 69(11), 312-313. doi:10.15585/mmwr.mm6911e2 Kelly, H., \& Cowling, B. J. (2013). Case fatality: rate, ratio, or risk? Epidemiology, 24(4), 622-623. doi:10.1097/EDE.0b013e318296c2b6

Khajah, M. A., Fateel, M. M., Ananthalakshmi, K. V., \& Luqmani, Y. A. (2016). Anti-inflammatory action of angiotensin 1-7 in experimental colitis. PLoS One, $11(3)$

Khan, S., Siddique, R., Shereen, M. A., Ali, A., Liu, J., Bai, Q., . . Xue, M. (2020). The emergence of a novel coronavirus (SARS-CoV-2), their biology and therapeutic options. J Clin Microbiol, doi:10.1128/JCM.00187-20

Kim, J. M., Chung, Y. S., Jo, H. J., Lee, N. J., Kim, M. S., Woo, S. H., . . Han, M. G. (2020). Identification of Coronavirus Isolated from a Patient in Korea with COVID-19. Osong Public Health Res Perspect, 11(1), 3-7. doi:10.24171/j.phrp.2020.11.1.02
Kobayashi, Y., \& Mitsudomi, T. (2013). Management of ground-glass opacities: should all pulmonary lesions with ground-glass opacity be surgically resected? Transl Lung Cancer Res, 2(5), 354-363. doi:10.3978/j.issn.2218-6751.2013.09.03 Kucharski, A. J., Russell, T. W., Diamond, C., Liu, Y., Edmunds, J., Funk, S., . . Centre for Mathematical Modelling of Infectious Diseases, C.-w. g. (2020). Early dynamics of transmission and control of COVID-19: a mathematical modelling study. Lancet Infect Dis. doi:10.1016/S1473-3099(20)30144-4

Kumar, A., Singh, H. N., Pareek, V., Raza, K., Dantham, S., Kumar, P., . . Faiq, M. A. (2016). A Possible Mechanism of Zika Virus Associated Microcephaly: Imperative Role of Retinoic Acid Response Element (RARE) Consensus Sequence Repeats in the Viral Genome. Front Hum Neurosci, 10, 403 doi: $10.3389 /$ fnhum.2016.00403

Lai, C. C., Shih, T. P., Ko, W. C., Tang, H. J., \& Hsueh, P. R. (2020). Severe acute respiratory syndrome coronavirus 2 (SARS-CoV-2) and coronavirus disease-2019 (COVID-19): The epidemic and the challenges. Int J Antimicrob Agents, 55(3), 105924. doi:10.1016/j.ijantimicag.2020.105924

Lam, T. T., Shum, M. H., Zhu, H. C., Tong, Y. G., Ni, X. B., Liao, Y. S., . . Guan, Y. (2020). Identifying SARS-CoV-2 related coronaviruses in Malayan pangolins. Nature. doi:10.1038/s41586-020-2169-0

Lan, L., Xu, D., Ye, G., Xia, C., Wang, S., Li, Y., \& Xu, H. (2020). Positive RTPCR Test Results in Patients Recovered From COVID-19. JAMA. doi:10.1001/jama.2020.2783

Lau, S. K. P., Fan, R. Y. Y., Luk, H. K. H., Zhu, L., Fung, J., Li, K. S. M., . . Woo, P. C. Y. (2018). Replication of MERS and SARS coronaviruses in bat cells offers insights to their ancestral origins. Emerg Microbes Infect, 7(1), 209 doi:10.1038/s41426-018-0208-9

Lauer, S. A., Grantz, K. H., Bi, Q., Jones, F. K., Zheng, Q., Meredith, H. R., . . Lessler, J. (2020). The Incubation Period of Coronavirus Disease 2019 (COVID19) From Publicly Reported Confirmed Cases: Estimation and Application. Ann Intern Med. doi:10.7326/M20-0504

Levy, J. W., Cowling, B. J., Simmerman, J. M., Olsen, S. J., Fang, V. J., Suntarattiwong, P., . . Chotipitayasunondh, T. (2013). The serial intervals of seasonal and pandemic influenza viruses in households in Bangkok, Thailand. Am J Epidemiol, 177(12), 1443-1451. doi:10.1093/aje/kws402

Lewnard, J. A., \& Lo, N. C. (2020). Scientific and ethical basis for socialdistancing interventions against COVID-19. Lancet Infect Dis. doi:10.1016/S1473-3099(20)30190-0

Li Q, Guan X, Wu P et al. Early transmission dynamics in Wuhan, China, of nove coronavirus-Infected pneumonia. N Engl J Med 2020 Jan 29 doi:10.1056/NEJMoa2001316

Li, F., \& Du, L. (2019). MERS Coronavirus: An Emerging Zoonotic Virus Viruses, 11(7). doi:10.3390/v11070663

Li, J. O., Lam, D. S. C., Chen, Y., \& Ting, D. S. W. (2020). Novel Coronavirus disease 2019 (COVID-19): The importance of recognising possible early ocular manifestation and using protective eyewear. Br J Ophthalmol, 104(3), 297-298. doi:10.1136/bjophthalmol-2020-315994

Li, L. Q., Huang, T., Wang, Y. Q., Wang, Z. P., Liang, Y., Huang, T. B., .. W Wang, Y. (2020). 2019 novel coronavirus patients' clinical characteristics, discharge rate, and fatality rate of meta-analysis. J Med Virol. doi:10.1002/jmv.25757 
Li, W., Cui, H., Li, K., Fang, Y., \& Li, S. (2020). Chest computed tomography in children with COVID-19 respiratory infection. Pediatr Radiol, doi:10.1007/s00247-020-04656-7

Li, X., Zai, J., Zhao, Q., Nie, Q., Li, Y., Foley, B. T., \& Chaillon, A. (2020). Evolutionary history, potential intermediate animal host, and cross-species analyses of SARS-CoV-2. J Med Virol. doi:10.1002/jmv.25731

Li, Y., \& Xia, L. (2020). Coronavirus Disease 2019 (COVID-19): Role of Chest $\mathrm{CT}$ in Diagnosis and Management. AJR Am J Roentgenol, 1-7. doi:10.2214/AJR.20.22954

Li, Y., Guo, Y. P., Wong, K. C., Chung, W. Y., Gohel, M. D., \& Leung, H. M. (2008). Transmission of communicable respiratory infections and facemasks. J Multidiscip Healthc, 1, 17-27. doi:10.2147/jmdh.s3019

Li, Y., Yao, L., Li, J., Chen, L., Song, Y., Cai, Z., \& Yang, C. (2020). Stability Issues of RT-PCR Testing of SARS-CoV-2 for Hospitalized Patients Clinically Diagnosed with COVID-19. J Med Virol. doi:10.1002/jmv.25786

Lim, J., Jeon, S., Shin, H. Y., Kim, M. J., Seong, Y. M., Lee, W. J., . . Park, S. J. (2020). Case of the Index Patient Who Caused Tertiary Transmission of COVID19 Infection in Korea: the Application of Lopinavir/Ritonavir for the Treatment of COVID-19 Infected Pneumonia Monitored by Quantitative RT-PCR. J Korean Med Sci, 35(6), e79. doi:10.3346/jkms.2020.35.e79

Lim, W., Ng, K. C., \& Tsang, D. N. (2006). Laboratory containment of SARS virus. Ann Acad Med Singapore, 35(5), 354-360.

Lin, C., Ding, Y., Xie, B., Sun, Z., Li, X., Chen, Z., \& Niu, M. (2020). Asymptomatic novel coronavirus pneumonia patient outside Wuhan: The value of CT images in the course of the disease. Clin Imaging, 63, 7-9. doi:10.1016/j.clinimag.2020.02.008

Liu, L., Wei, J., Li, Y., \& Ooi, A. (2017). Evaporation and dispersion of respiratory droplets from coughing. Indoor Air, 27(1), 179-190. doi:10.1111/ina.12297

Liu, Y., Gayle, A. A., Wilder-Smith, A., \& Rocklov, J. (2020). The reproductive number of COVID-19 is higher compared to SARS coronavirus. J Travel Med, 27(2). doi:10.1093/jtm/taaa021

Liu, Z., Xiao, X., Wei, X., Li, J., Yang, J., Tan, H., . . Liu, L. (2020). Composition and divergence of coronavirus spike proteins and host ACE2 receptors predict potential intermediate hosts of SARS-CoV-2. J Med Virol. doi:10.1002/jmv.25726 Lo, N. C., Gupta, R., Stanaway, J. D., Garrett, D. O., Bogoch, II, Luby, S. P., \& Andrews, J. R. (2018). Comparison of Strategies and Incidence Thresholds for Vi Conjugate Vaccines Against Typhoid Fever: A Cost-effectiveness Modeling Study. J Infect Dis, 218(suppl_4), S232-S242. doi:10.1093/infdis/jix598

Losa Garcia, J. E., Rodriguez, F. M., Martin de Cabo, M. R., Garcia Salgado, M. J., Losada, J. P., Villaron, L. G., . . . Arellano, J. L. (1999). Evaluation of inflammatory cytokine secretion by human alveolar macrophages. Mediators Inflamm, 8(1), 43-51. doi:10.1080/09629359990711

Lu, S., Lin, J., Zhang, Z., Xiao, L., Jiang, Z., Chen, J., . . Luo, S. (2020). Alert for non-respiratory symptoms of Coronavirus Disease 2019 (COVID-19) patients in epidemic period: A case report of familial cluster with three asymptomatic COVID-19 patients. J Med Virol. doi:10.1002/jmv.25776

Majumder, M. S., Rivers, C., Lofgren, E., \& Fisman, D. (2014). Estimation of MERS-Coronavirus Reproductive Number and Case Fatality Rate for the Spring
2014 Saudi Arabia Outbreak: Insights from Publicly Available Data. PLoS Curr, 6. doi:10.1371/currents.outbreaks.98d2f8f3382d84f390736cd5f5fe133c Mandal, S., Bhatnagar, T., Arinaminpathy, N., Agarwal, A., Chowdhury, A., Murhekar, M., . . . Sarkar, S. (2020). Prudent public health intervention strategies to control the coronavirus disease 2019 transmission in India: A mathematical model-based approach. Indian J Med Res. doi:10.4103/ijmr.IJMR 504_20

Marr, L. C., Tang, J. W., Van Mullekom, J., \& Lakdawala, S. S. (2019). Mechanistic insights into the effect of humidity on airborne influenza virus survival, transmission and incidence. J R Soc Interface, 16(150), 20180298. doi:10.1098/rsif.2018.0298

Martinez, M. A. (2020). Compounds with therapeutic potential against novel respiratory 2019 coronavirus. Antimicrob Agents Chemother. doi:10.1128/AAC.00399-20

McIntyre, W., Netzband, R., Bonenfant, G., Biegel, J. M., Miller, C., Fuchs, G., . . Pager, C. T. (2018). Positive-sense RNA viruses reveal the complexity and dynamics of the cellular and viral epitranscriptomes during infection. Nucleic Acids Res, 46(11), 5776-5791. doi:10.1093/nar/gky029

Meijers, J. M. (1990). Comparing biological effects of mineral fibres. Br J Ind Med, 47(4), 286-287. doi:10.1136/oem.47.4.286-b

Meo, S. A., Alhowikan, A. M., Al-Khlaiwi, T., Meo, I. M., Halepoto, D. M., Iqbal, M., , . Ahmed, N. (2020). Novel coronavirus 2019-nCoV: prevalence, biological and clinical characteristics comparison with SARS-CoV and MERS-CoV. Eur Rev Med Pharmacol Sci, 24(4), 2012-2019. doi:10.26355/eurrev_202002_20379 Mian, A., \& Khan, S. (2020). Coronavirus: the spread of misinformation. BMC Med, 18(1), 89. doi:10.1186/s12916-020-01556-3

Milne-Price, S., Miazgowicz, K. L., \& Munster, V. J. (2014). The emergence of the Middle East respiratory syndrome coronavirus. Pathog Dis, 71(2), 121-136. doi:10.1111/2049-632X.12166

Mizumoto, K., Kagaya, K., Zarebski, A., \& Chowell, G. (2020). Estimating the asymptomatic proportion of coronavirus disease 2019 (COVID-19) cases on board the Diamond Princess cruise ship, Yokohama, Japan, 2020. Euro Surveill, 25(10). doi:10.2807/1560-7917.ES.2020.25.10.2000180

Moro, F., Buonsenso, D., Moruzzi, M. C., Inchingolo, R., Smargiassi, A., Demi, L., . . Testa, A. C. (2020). How to perform lung ultrasound in pregnant women with suspected COVID-19 infection. Ultrasound Obstet Gynecol. doi:10.1002/uog. 22028

Mossel, E. C., Wang, J., Jeffers, S., Edeen, K. E., Wang, S., Cosgrove, G. P., . . Mason, R. J. (2008). SARS-CoV replicates in primary human alveolar type II cell cultures but not in type I-like cells. Virology, 372(1), 127-135. doi:10.1016/j.virol.2007.09.045

Mulangu, S., Dodd, L. E., Davey, R. T., Jr., Tshiani Mbaya, O., Proschan, M., Mukadi, D., . . Team, P. C. S. (2019). A Randomized, Controlled Trial of Ebola Virus Disease Therapeutics. N Engl J Med, 381(24), 2293-2303. doi:10.1056/NEJMoa1910993

Murdoch, D. R., \& French, N. P. (2020). COVID-19: another infectious disease emerging at the animal-human interface. N Z Med J, 133(1510), 12-15.

Naeem, A., Rai, S. N., \& Pierre, L. (2020). Histology, Alveolar Macrophages. In StatPearls. Treasure Island (FL). 
Nikitin, N., Petrova, E., Trifonova, E., \& Karpova, O. (2014). Influenza virus aerosols in the air and their infectiousness. Adv Virol, 2014, 859090. doi: $10.1155 / 2014 / 859090$

Nishiura, H., Linton, N. M., \& Akhmetzhanov, A. R. (2020). Serial interval of novel coronavirus (COVID-19) infections. Int J Infect Dis, 93, 284-286. doi:10.1016/j.ijid.2020.02.060

Ocaranza, M. P., \& Jalil, J. E. (2012). Protective Role of the ACE2/Ang-(1-9) Axis in Cardiovascular Remodeling. Int J Hypertens, 2012, 594361. doi: $10.1155 / 2012 / 594361$

Onder, G., Rezza, G., \& Brusaferro, S. (2020). Case-Fatality Rate and Characteristics of Patients Dying in Relation to COVID-19 in Italy. JAMA. doi:10.1001/jama.2020.4683

Ong SWX, Tan YK, Chia PY, et al. Air, Surface Environmental, and Personal Protective Equipment Contamination by Severe Acute Respiratory Syndrome Coronavirus 2 (SARS-CoV-2) From a Symptomatic Patient. JAMA. Published online March 04, 2020. doi:10.1001/jama.2020.3227

Ortega, J. T., Serrano, M. L., Pujol, F. H., \& Rangel, H. R. (2020). Role of changes in SARS-CoV-2 spike protein in the interaction with the human ACE2 receptor: An in silico analysis. EXCLI J, 19, 410-417. doi:10.17179/excli2020-1167

Park, S. C., \& Park, Y. C. (2020). Mental Health Care Measures in Response to the 2019 Novel Coronavirus Outbreak in Korea. Psychiatry Investig, 17(2), 85-86. doi:10.30773/pi.2020.0058

Parmet, W. E., \& Sinha, M. S. (2020). Covid-19 - The Law and Limits of Quarantine. N Engl J Med. doi:10.1056/NEJMp2004211

Parvin, J. D., Moscona, A., Pan, W. T., Leider, J. M., \& Palese, P. (1986). Measurement of the mutation rates of animal viruses: influenza A virus and poliovirus type 1. J Virol, 59(2), 377-383

Peeri, N. C., Shrestha, N., Rahman, M. S., Zaki, R., Tan, Z., Bibi, S., . . Haque, U. (2020). The SARS, MERS and novel coronavirus (COVID-19) epidemics, the newest and biggest global health threats: what lessons have we learned? Int $\mathrm{J}$ Epidemiol. doi:10.1093/ije/dyaa033

Pelat, C., Ferguson, N. M., White, P. J., Reed, C., Finelli, L., Cauchemez, S., \& Fraser, C. (2014). Optimizing the precision of case fatality ratio estimates under the surveillance pyramid approach. Am J Epidemiol, 180(10), 1036-1046. doi:10.1093/aje/kwu213

Peng, X., Xu, X., Li, Y., Cheng, L., Zhou, X., \& Ren, B. (2020). Transmission routes of 2019-nCoV and controls in dental practice. Int J Oral Sci, 12(1), 9. doi:10.1038/s41368-020-0075-9

Peto, J. (2020). Covid-19 mass testing facilities could end the epidemic rapidly. BMJ, 368, m1163. doi:10.1136/bmj.m1163

Petropoulos, F., \& Makridakis, S. (2020). Forecasting the novel coronavirus COVID-19. PLoS One, 15(3), e0231236. doi:10.1371/journal.pone.0231236

Phelan, A. L., Katz, R., \& Gostin, L. O. (2020). The Novel Coronavirus Originating in Wuhan, China: Challenges for Global Health Governance. JAMA. doi:10.1001/jama.2020.1097

Poltronieri, P., Sun, B., \& Mallardo, M. (2015). RNA Viruses: RNA Roles in Pathogenesis, Coreplication and Viral Load. Curr Genomics, 16(5), 327-335. doi:10.2174/1389202916666150707160613
Porcheddu, R., Serra, C., Kelvin, D., Kelvin, N., \& Rubino, S. (2020). Similarity in Case Fatality Rates (CFR) of COVID-19/SARS-COV-2 in Italy and China. J Infect Dev Ctries, 14(2), 125-128. doi:10.3855/jidc. 12600 Portnoy, J., Waller, M., \& Elliott, T. (2020). Telemedicine in the Era of COVID19. J Allergy Clin Immunol Pract. doi:10.1016/j.jaip.2020.03.008 Powers, K. A., \& Dhamoon, A. S. (2020). Physiology, Pulmonary, Ventilation and Perfusion. In StatPearls. Treasure Island (FL)

Prompetchara, E., Ketloy, C., \& Palaga, T. (2020). Immune responses in COVID19 and potential vaccines: Lessons learned from SARS and MERS epidemic. Asian Pac J Allergy Immunol, 38(1), 1-9. doi:10.12932/AP-200220-0772

Qian, Z., Travanty, E. A., Oko, L., Edeen, K., Berglund, A., Wang, J., . . Mason, R. J. (2013). Innate immune response of human alveolar type II cells infected with severe acute respiratory syndrome-coronavirus. Am J Respir Cell Mol Biol, 48(6), 742-748. doi:10.1165/rcmb.2012-0339OC

Qu, G., Li, X., Hu, L., \& Jiang, G. (2020). An Imperative Need for Research on the Role of Environmental Factors in Transmission of Novel Coronavirus (COVID19). Environ Sci Technol. doi:10.1021/acs.est.0c01102

Quinn, S. C., \& Kumar, S. (2014). Health inequalities and infectious disease epidemics: a challenge for global health security. Biosecur Bioterror, 12(5), 263273. doi: $10.1089 /$ bsp.2014.0032

Rapoport, B. (1991). Pathophysiology of Hashimoto's thyroiditis and $\begin{array}{llll}\text { hypothyroidism. Annu } & \text { Rev } & \text { Med, } & \text { 42, }\end{array}$ doi:10.1146/annurev.me.42.020191.000515

Reich, N. G., Lessler, J., Cummings, D. A., \& Brookmeyer, R. (2012). Estimating absolute and relative case fatality ratios from infectious disease surveillance data Biometrics, 68(2), 598-606. doi:10.1111/j.1541-0420.2011.01709.x

Richards, A. L., \& Jackson, W. T. (2013). How positive-strand RNA viruses benefit from autophagosome maturation. J Virol, 87(18), 9966-9972. doi:10.1128/JVI.00460-13

Ridenhour, B., Kowalik, J. M., \& Shay, D. K. (2014). Unraveling R0: considerations for public health applications. Am J Public Health, 104(2), e32-41. doi:10.2105/AJPH.2013.301704

Riou, J., \& Althaus, C. L. (2020). Pattern of early human-to-human transmission of Wuhan 2019 novel coronavirus (2019-nCoV), December 2019 to January 2020. Euro Surveill, 25(4). doi:10.2807/1560-7917.ES.2020.25.4.2000058

Roca-Ho, H., Riera, M., Palau, V., Pascual, J., \& Soler, M. J. (2017) Characterization of ACE and ACE2 Expression within Different Organs of the NOD Mouse. Int J Mol Sci, 18(3). doi:10.3390/ijms18030563

Rodriguez-Morales, A. J., Bonilla-Aldana, D. K., Balbin-Ramon, G. J., Rabaan, A A., Sah, R., Paniz-Mondolfi, A., . . Esposito, S. (2020). History is repeating itself: Probable zoonotic spillover as the cause of the 2019 novel Coronavirus Epidemic. Infez Med, 28(1), 3-5.

Roosa, K., Lee, Y., Luo, R., Kirpich, A., Rothenberg, R., Hyman, J. M., . . Chowell, G. (2020). Real-time forecasts of the COVID-19 epidemic in China from February 5th to February 24th, 2020. Infect Dis Model, 5, 256-263. doi:10.1016/j.idm.2020.02.002

Salata, C., Calistri, A., Parolin, C., \& Palu, G. (2019). Coronaviruses: a paradigm of new emerging zoonotic diseases. Pathog Dis, 77(9). doi:10.1093/femspd/ftaa006 
Santacroce, L., Bottalico, L., \& Charitos, I. A. (2020). The Impact of COVID-19 on Italy: A Lesson for the Future. Int $\mathrm{J}$ Occup Environ Med. doi:10.34172/ijoem.2020.1984

Satija, N., \& Lal, S. K. (2007). The molecular biology of SARS coronavirus. Ann N Y Acad Sci, 1102, 26-38. doi:10.1196/annals. 1408.002

Sharif-Yakan, A., \& Kanj, S. S. (2014). Emergence of MERS-CoV in the Middle East: origins, transmission, treatment, and perspectives. PLoS Pathog, 10(12), e1004457. doi:10.1371/journal.ppat.1004457

Shi, X., Gong, E., Gao, D., Zhang, B., Zheng, J., Gao, Z., ... \& Liao, S. (2005). Severe acute respiratory syndrome associated coronavirus is detected in intestinal tissues of fatal cases. American Journal of Gastroenterology, 100(1), 169-176.

Shi, Z., \& Hu, Z. (2008). A review of studies on animal reservoirs of the SARS coronavirus. Virus Res, 133(1), 74-87. doi:10.1016/j.virusres.2007.03.012

Shim, E., Tariq, A., Choi, W., Lee, Y., \& Chowell, G. (2020). Transmission potential and severity of COVID-19 in South Korea. Int J Infect Dis. doi:10.1016/j.ijid.2020.03.031

Sims, A. C., Burkett, S. E., Yount, B., \& Pickles, R. J. (2008). SARS-CoV replication and pathogenesis in an in vitro model of the human conducting airway epithelium. Virus Res, 133(1), 33-44. doi:10.1016/j.virusres.2007.03.013 Singhal, T. (2020). A Review of Coronavirus Disease-2019 (COVID-19). Indian J Pediatr, 87(4), 281-286. doi:10.1007/s12098-020-03263-6

Smith, A. C., Thomas, E., Snoswell, C. L., Haydon, H., Mehrotra, A., Clemensen, J., \& Caffery, L. J. (2020). Telehealth for global emergencies: Implications for coronavirus disease 2019 (COVID-19). J Telemed Telecare, 1357633X20916567. doi: $10.1177 / 1357633 \times 20916567$

Soldati, G., Smargiassi, A., Inchingolo, R., Buonsenso, D., Perrone, T., Briganti, D. F., . . Demi, L. (2020). Is there a role for lung ultrasound during the COVID19 pandemic? J Ultrasound Med. doi:10.1002/jum.15284

South, A.M., Tomlinson, L., Edmonston, D. et al. Controversies of reninangiotensin system inhibition during the COVID-19 pandemic. Nat Rev Nephrol (2020). https://doi.org/10.1038/s41581-020-0279-4

Stilianakis, N. I., \& Drossinos, Y. (2010). Dynamics of infectious disease transmission by inhalable respiratory droplets. J R Soc Interface, 7(50), 1355-1366. doi:10.1098/rsif.2010.0026

Sugahara, K. (1994). [Regulation of alveolar type II cell proliferation and surfactant gene expression]. Nihon Kyobu Shikkan Gakkai Zasshi, 32 Suppl, 7378.

Sun, P., Lu, X., Xu, C., Sun, W., \& Pan, B. (2020). Understanding of COVID-19 based on current evidence. J Med Virol. doi:10.1002/jmv.25722

Sun, Z., Thilakavathy, K., Kumar, S. S., He, G., \& Liu, S. V. (2020). Potential Factors Influencing Repeated SARS Outbreaks in China. Int J Environ Res Public Health, 17(5). doi:10.3390/ijerph17051633

Tang, B., Xia, F., Tang, S., Bragazzi, N. L., Li, Q., Sun, X., . . Wu, J. (2020). The effectiveness of quarantine and isolation determine the trend of the COVID-19 epidemics in the final phase of the current outbreak in China. Int J Infect Dis. doi:10.1016/j.jiid.2020.03.018

Tchesnokov, E. P., Feng, J. Y., Porter, D. P., \& Gotte, M. (2019). Mechanism of Inhibition of Ebola Virus RNA-Dependent RNA Polymerase by Remdesivir. Viruses, 11(4). doi:10.3390/v11040326
Telemedicine services thrive during Covid-19. (2020). Vet Rec, 186(12), 365 doi: $10.1136 /$ vr.m1231

ten Asbroek, A. H., Borgdorff, M. W., Nagelkerke, N. J., Sebek, M. M., Deville, W., van Embden, J. D., \& van Soolingen, D. (1999). Estimation of serial interval and incubation period of tuberculosis using DNA fingerprinting. Int J Tuberc Lung Dis, 3(5), 414-420.

Tian, S., Hu, W., Niu, L., Liu, H., Xu, H., \& Xiao, S. Y. (2020). Pulmonary Pathology of Early-Phase 2019 Novel Coronavirus (COVID-19) Pneumonia in Two Patients With Lung Cancer. J Thorac Oncol. doi:10.1016/j.jtho.2020.02.010 Tian, X., Li, C., Huang, A., Xia, S., Lu, S., Shi, Z., . . Y Ying, T. (2020). Potent binding of 2019 novel coronavirus spike protein by a SARS coronavirus-specific human monoclonal antibody. Emerg Microbes Infect, 9(1), 382-385. doi: $10.1080 / 22221751.2020 .1729069$

Tikellis, C., \& Thomas, M. C. (2012). Angiotensin-Converting Enzyme 2 (ACE2 Is a Key Modulator of the Renin Angiotensin System in Health and Disease. Int J Pept, 2012, 256294. doi:10.1155/2012/256294

Tu, C., Crameri, G., Kong, X., Chen, J., Sun, Y., Yu, M., . . Wang, L. F. (2004). Antibodies to SARS coronavirus in civets. Emerg Infect Dis, 10(12), 2244-2248. doi:10.3201/eid1012.040520

Turner, A. J., Hiscox, J. A., \& Hooper, N. M. (2004). ACE2: from vasopeptidase to SARS virus receptor. Trends in pharmacological sciences, 25(6), 291-294. van den Driessche, P. (2017). Reproduction numbers of infectious disease models Infect Dis Model, 2(3), 288-303. doi:10.1016/j.idm.2017.06.002

van Doremalen, N., Bushmaker, T., Morris, D. H., Holbrook, M. G., Gamble, A., Williamson, B. N., . . Munster, V. J. (2020). Aerosol and Surface Stability of SARS-CoV-2 as Compared with SARS-CoV-1. N Engl J Med doi:10.1056/NEJMc2004973

van Staden C. COVID-19 and the crisis of national development. Nat Hum Behav. 2020 Mar $23: 1-2$

Vankadari, N., \& Wilce, J. A. (2020). Emerging WuHan (COVID-19) coronavirus: glycan shield and structure prediction of spike glycoprotein and its interaction with human CD26. Emerg Microbes Infect, 9(1), 601-604. doi:10.1080/22221751.2020.1739565

Varagic, J., Ahmad, S., Nagata, S., \& Ferrario, C. M. (2014). ACE2: angiotensin II/angiotensin-(1-7) balance in cardiac and renal injury. Curr Hypertens Rep, 16(3), 420. doi:10.1007/s11906-014-0420-5

Velavan, T. P., \& Meyer, C. G. (2020). The COVID-19 epidemic. Trop Med In Health, 25(3), 278-280. doi:10.1111/tmi.13383

Venkataraman, S., Prasad, B., \& Selvarajan, R. (2018). RNA Dependent RNA Polymerases: Insights from Structure, Function and Evolution. Viruses, 10(2). doi: $10.3390 / \mathrm{v} 10020076$

Vijayanand, P., Wilkins, E., \& Woodhead, M. (2004). Severe acute respiratory syndrome (SARS): a review. Clin Med (Lond), 4(2), 152-160. doi:10.7861/clinmedicine.4-2-152

Vijgen, L., Keyaerts, E., Moes, E., Thoelen, I., Wollants, E., Lemey, P., . . Van Ranst, M. (2005). Complete genomic sequence of human coronavirus OC43: molecular clock analysis suggests a relatively recent zoonotic coronavirus transmission event. J Virol, 79(3), 1595-1604. doi:10.1128/JVI.79.3.15951604.2005 
Vink, M. A., Bootsma, M. C., \& Wallinga, J. (2014). Serial intervals of respiratory infectious diseases: a systematic review and analysis. Am J Epidemiol, 180(9), 865-875. doi:10.1093/aje/kwu209

Vynnycky, E., \& Fine, P. E. (2000). Lifetime risks, incubation period, and serial interval of tuberculosis. Am J Epidemiol, 152(3), 247-263. doi:10.1093/aje/152.3.247

Wan KH , Huang SS, Young A, Lam DC. Precautionary Measures Needed for Ophthalmologists During Pandemic of the Coronavirus Disease 2019 (COVID19). Acta Ophthalmol. 2020 Mar 29.

Wan, S., Xiang, Y., Fang, W., Zheng, Y., Li, B., Hu, Y., . . Y Yang, R. (2020). Clinical features and treatment of COVID-19 patients in northeast Chongqing. J Med Virol. doi:10.1002/jmv.25783

Wang, L. F., Shi, Z., Zhang, S., Field, H., Daszak, P., \& Eaton, B. T. (2006). Review of bats and SARS. Emerg Infect Dis, 12(12), 1834-1840. doi:10.3201/eid1212.060401

Wang, L., \& Wu, J. T. (2018). Characterizing the dynamics underlying global spread of epidemics. Nat Commun, 9(1), 218. doi:10.1038/s41467-017-02344-Z

Wang, R. Y., \& Li, K. (2012). Host factors in the replication of positive-strand RNA viruses. Chang Gung Med J, 35(2), 111-124. doi:10.4103/2319-4170.106160 Wang, Y., Wang, Y., Chen, Y., \& Qin, Q. (2020). Unique epidemiological and clinical features of the emerging 2019 novel coronavirus pneumonia (COVID-19) implicate special control measures. J Med Virol. doi:10.1002/jmv.25748

Ward, H. E., \& Nicholas, T. E. (1984). Alveolar type I and type II cells. Aust N Z J Med, 14(5 Suppl 3), 731-734.

Warnes, S. L., Little, Z. R., \& Keevil, C. W. (2015). Human Coronavirus 229E Remains Infectious on Common Touch Surface Materials. mBio, 6(6), e0169701615. doi:10.1128/mBio.01697-15

Weber, D. J., \& Rutala, W. A. (1999). Zoonotic infections. Occup Med, 14(2), 247284.

Wells, C. R., Sah, P., Moghadas, S. M., Pandey, A., Shoukat, A., Wang, Y., .. . Galvani, A. P. (2020). Impact of international travel and border control measures on the global spread of the novel 2019 coronavirus outbreak. Proc Natl Acad Sci U S A. doi:10.1073/pnas.2002616117

Wilder-Smith, A., Chiew, C. J., \& Lee, V. J. (2020). Can we contain the COVID19 outbreak with the same measures as for SARS? Lancet Infect Dis. doi:10.1016/S1473-3099(20)30129-8

Wilf-Miron, R., Lewenhoff, I., Benyamini, Z., \& Aviram, A. (2003). From aviation to medicine: applying concepts of aviation safety to risk management in ambulatory care. Qual Saf Health Care, 12(1), 35-39. doi:10.1136/qhc.12.1.35 Wilson, N., Kvalsvig, A., Barnard, L. T., \& Baker, M. G. (2020). Case-Fatality Risk Estimates for COVID-19 Calculated by Using a Lag Time for Fatality. Emerg Infect Dis, 26(6). doi:10.3201/eid2606.200320

World Health Organization. Report of the WHO-China Joint Mission on Coronavirus Disease 2019 (COVID-19) 2020 [cited 20 March 2020]. Available from: https://www.who.int/docs/default-source/coronaviruse/who-china-jointmission-on-covid- 19-final-report.pdf World Health Organization. WHO Director-General's remarks at the media briefing on 2019-nCoV on 11 February 2020. 2020. at https://www.who.int/dg/speeches/detail/who-director-general-s-remarks-at-themedia-briefing-on-2019-ncov-on-11-february-2020.

Wu, J., Wu, X., Zeng, W., Guo, D., Fang, Z., Chen, L., . . Li, C. (2020). Chest CT Findings in Patients with Corona Virus Disease 2019 and its Relationship with Clinical Features. Invest Radiol. doi:10.1097/RLI.0000000000000670

Wu, Y. C., Chen, C. S., \& Chan, Y. J. (2020). The outbreak of COVID-19: An $\begin{array}{lllll}\text { overview. J } & \text { 217-220. }\end{array}$ doi:10.1097/JCMA.0000000000000270

Wu, Y., Guo, C., Tang, L., Hong, Z., Zhou, J., Dong, X., . . Huang, X. (2020). Prolonged presence of SARS-CoV-2 viral RNA in faecal samples. Lancet Gastroenterol Hepatol. doi:10.1016/S2468-1253(20)30083-2

Xie, X., Li, Y., Chwang, A. T., Ho, P. L., \& Seto, W. H. (2007). How far droplets can move in indoor environments--revisiting the Wells evaporation-falling curve. Indoor Air, 17(3), 211-225. doi:10.1111/j.1600-0668.2007.00469.x

Xie, X., Li, Y., Sun, H., \& Liu, L. (2009). Exhaled droplets due to talking and $\begin{array}{llllllll}\text { coughing. } \mathrm{J} & \mathrm{R} & \mathrm{Soc} & \text { Interface, } & 6 & \text { Suppl } & 6 \text {, } & \text { S703-714. }\end{array}$ doi:10.1098/rsif.2009.0388.focus

Xu, R. H., He, J. F., Evans, M. R., Peng, G. W., Field, H. E., Yu, D. W., . . Schnur, A. (2004). Epidemiologic clues to SARS origin in China. Emerg Infect Dis, 10(6), 1030-1037. doi:10.3201/eid1006.030852

Yang, P., \& Wang, X. (2020). COVID-19: a new challenge for human beings. Cell Mol Immunol. doi:10.1038/s41423-020-0407-x

Yang, S., Cao, P., Du, P., Wu, Z., Zhuang, Z., Yang, L., . . He, D. (2020). Early estimation of the case fatality rate of COVID-19 in mainland China: a data-driven analysis. Ann Transl Med, 8(4), 128. doi:10.21037/atm.2020.02.66

Yang, W., \& Yan, F. (2020). Patients with RT-PCR Confirmed COVID-19 and Normal Chest CT. Radiology, 200702. doi:10.1148/radiol.2020200702

Yao, T. T., Qian, J. D., Zhu, W. Y., Wang, Y., \& Wang, G. Q. (2020). A systematic review of lopinavir therapy for SARS coronavirus and MERS coronavirus-A possible reference for coronavirus disease-19 treatment option. J Med Virol. doi:10.1002/jmv. 25729

Yeo, C., Kaushal, S., \& Yeo, D. (2020). Enteric involvement of coronaviruses: is faecal-oral transmission of SARS-CoV-2 possible? Lancet Gastroenterol Hepatol, 5(4), 335-337. doi:10.1016/S2468-1253(20)30048-0

Yoon, S. H., Lee, K. H., Kim, J. Y., Lee, Y. K., Ko, H., Kim, K. H., . . Kim, Y. H. (2020). Chest Radiographic and CT Findings of the 2019 Novel Coronavirus Disease (COVID-19): Analysis of Nine Patients Treated in Korea. Korean J Radiol, 21(4), 494-500. doi:10.3348/kjr.2020.0132

Yoshikura, H. (2012). On case-fatality rate: review and hypothesis. Jpn J Infect Dis, 65(4), 279-288. doi:10.7883/yoken.65.279

Young BE, Ong SWX, Kalimuddin S, et al. Epidemiologic Features and Clinical Course of Patients Infected With SARS-CoV-2 in Singapore. JAMA. Published online March 03, 2020. doi:10.1001/jama.2020.3204

Yu, H., Liu, S., Zhang, C., Li, S., Ren, J., Zhang, J., \& Xu, W. (2018). Computed tomography and pathology evaluation of lung ground-glass opacity. Exp Ther Med, 16(6), 5305-5309. doi:10.3892/etm.2018.6886

Yuen, K. S., Ye, Z. W., Fung, S. Y., Chan, C. P., \& Jin, D. Y. (2020). SARS-CoV2 and COVID-19: The most important research questions. Cell Biosci, 10, 40. doi:10.1186/s13578-020-00404-4 
Zhang, H., Zhou, P., Wei, Y., Yue, H., Wang, Y., Hu, M., . . Du, R. (2020). Histopathologic Changes and SARS-CoV-2 Immunostaining in the Lung of a Patient With COVID-19. Ann Intern Med. doi:10.7326/M20-0533

Zhang, J., Tian, S., Lou, J., \& Chen, Y. (2020). Familial cluster of COVID-19 infection from an asymptomatic. Crit Care, 24(1), 119. doi:10.1186/s13054-020$2817-7$

Zhang, S., Diao, M., Yu, W., Pei, L., Lin, Z., \& Chen, D. (2020). Estimation of the reproductive number of novel coronavirus (COVID-19) and the probable outbreak size on the Diamond Princess cruise ship: A data-driven analysis. Int J Infect Dis, 93, 201-204. doi:10.1016/j.ijid.2020.02.033

Zhang, T., Wu, Q., \& Zhang, Z. (2020). Probable Pangolin Origin of SARS-CoV2 Associated with the COVID-19 Outbreak. Curr Biol. doi:10.1016/j.cub.2020.03.022

Zhang, X. A., Fan, H., Qi, R. Z., Zheng, W., Zheng, K., Gong, J. H., . . Liu, W. (2020). Importing coronavirus disease 2019 (COVID-19) into China after international air travel. Travel Med Infect Dis, 101620. doi:10.1016/j.tmaid.2020.101620

Zheng, Y. Y., Ma, Y. T., Zhang, J. Y., \& Xie, X. (2020). COVID-19 and the cardiovascular system. Nature Reviews Cardiology, 1-2.

Zhou, L., Liu, K., \& Liu, H. G. (2020). [Cause analysis and treatment strategies of "recurrence" with novel coronavirus pneumonia (covid-19) patients after discharge from hospital]. Zhonghua Jie $\mathrm{He} \mathrm{He} \mathrm{Hu} \mathrm{Xi}$ Za Zhi, 43(0), E028. doi:10.3760/cma.j.cn112147-20200229-00219

Zhou, S., Wang, Y., Zhu, T., \& Xia, L. (2020). CT Features of Coronavirus Disease 2019 (COVID-19) Pneumonia in 62 Patients in Wuhan, China. AJR Am J Roentgenol, 1-8. doi:10.2214/AJR.20.22975

Zhu N, Zhang D, Wang W et al. A novel coronavirus from patients with pneumonia in China, 2019. N Engl J Med 2020 Jan 24. doi: 10.1056/NEJMoa2001017. [Epub ahead of print]

Zhuang, Z., Zhao, S., Lin, Q., Cao, P., Lou, Y., Yang, L., \& He, D. (2020). Preliminary estimation of the novel coronavirus disease (COVID-19) cases in Iran: A modelling analysis based on overseas cases and air travel data. Int J Infect Dis. doi:10.1016/j.ijid.2020.03.019

Zinzula, L., \& Tramontano, E. (2013). Strategies of highly pathogenic RNA viruses to block dsRNA detection by RIG-I-like receptors: hide, mask, hit. Antiviral Res, 100(3), 615-635. doi:10.1016/j.antiviral.2013.10.002

Zou, L., Ruan, F., Huang, M., Liang, L., Huang, H., Hong, Z., ... \& Guo, Q. (2020). SARS-CoV-2 viral load in upper respiratory specimens of infected patients. New England Journal of Medicine, 382(12), 1177-1179. 